\title{
SISMOESTRATIGRAFIA DA FASE RIFTE DA PORÇÃO SUL DA BACIA DE CAMAMU
}

\section{PHASE RIFT SEISMIC STRATIGRAPHY OF THE SOUTHERN PORTION OF CAMAMU BASIN \\ Paulo Augusto Vidigal Duarte SOUZA; Daniel Bono Ribeiro VILAS BOAS; Michael HOLZ}

Universidade Federal da Bahia - UFBA/Instituto de Geociências (IGEO)/Departamento de Geologia e Geofísica. End. Rua. Barão de Jeremoabo, s/n - Ondina, Salvador - BA. Emails: daniel.bono@ufba.br; paulo.augusto@ufba.br; michael.holz@ufba.br.

\author{
Introdução \\ Estratigrafia de sequências aplicada a bacias rifte \\ Área de estudo/Banco de dados \\ Metodologia \\ Análise sismoestratigráfica \\ Embasamento e Pré-rifte \\ Sequência Rifte 1 \\ Sequência Rifte 2 \\ Sequência Rifte 3 \\ Sequência Rifte 4 \\ Sequência Rifte 5 \\ Sequência Rifte Total \\ Conclusões \\ Agradecimentos \\ Bibliografia
}

RESUMO - O trabalho consiste na interpretação regional de 91 linhas sísmicas 2D pós-empilhadas do sul da Bacia de Camamu. A análise é auxiliada pela interpretação de perfis geofísicos de 21 poços e um cubo sísmico 3D. A metodologia do trabalho fez uso da estratigrafia de sequências aplicada às bacias rifte e contemplou a confecção de sismogramas sintéticos de dados de poços para correlação com as linhas sísmicas. Atributos sísmicos foram utilizados na identificação de terminações estratais, superfícies estratigráficas e feições estruturais, como falhas e superfície do embasamento. O mapeamento estratigráfico da supersequência rifte evidenciou discordâncias internas segmentando-a em sequências de terceira ordem associadas o caráter episódico do tectonismo sofrido pelas bacias durante o período de rifteamento. A análise de tratos de sistemas só foi possível de ser realizada na região proximal da Bacia devido ao grande número de poços disponíveis para amarração. Como resultados da interpretação foi possível confeccionar mapas de espessura sísmica das sequências e juntamente com a análise estrutural, compreender os principais sistemas sedimentares atuantes nos diferentes estágios de rifteamento da bacia. Foram mapeadas além das discordâncias que delimitam a fase rifte (DSR e DPR), quatro discordâncias internas (DR2, DR3, DR4 e DR5), totalizando cinco sequências deposicionais de terceira ordem (Rifte 1, $2,3,4$ e 5). A separação em tratos tectônicos pelas superfícies estratigráficas só foi possível na região proximal devido ao grande número de poços e à boa confiabilidade das amarrações. A ZTS favoreceu uma maior criação de espaço principalmente durante a deposição do primeiro rifte.

Palavras-chave: Sismoestratigrafia, Rifte, Camamu.

\begin{abstract}
The work consists of seismic regional interpretation of 91 post-stacked 2D seismic lines from southern portion of Camamu Basin. The data base is also composed by 21 well geophysical profiles and a 3D seismic cube. As a work methodology, was used the seismic stratigraphy applied to rift basins and the synthetic seismograms generation to tie seismic-well data. Seismic attributes were used in the identification of stratigraphic terminations, stratigraphic surfaces and structural features, such as faults and basement surface. The stratigraphic mapping of rift supersequence evidenced internal unconformities by segmenting it in third order sequences associated with episodic character of the tectonism suffered by the basins during the rift period. The analysis of system tracts and their boundary stratigraphic surfaces was only possible in proximal region of the basin due to large number of wells available and the reliability of the ties. As result of the interpretation, it was possible to make sequence seismic thickness maps and, together with the structural analysis, understand the main sedimentary systems acting at the different stages of basin rifting. In addition to unconformity delimiting rift phase (DSR and DPR), were mapped four internal unconformities (DR2, DR3, DR4 and DR5), totalizing five third order depositional sequences (Rift 1,2,3,4 and 5). The ZTS favored greater creation of space mainly during the deposition of the first rift. Regarding the transitional phase, ware made two three-dimensional salt models in southern part of study area.
\end{abstract}

Keywords: Seismic stratigraphy, Rift, Camamu

\section{INTRODUÇÃO}

Com o aumento das necessidades energéticas, tornou-se necessário novas tecnologias e estudos em bacias sedimentares brasileiras.

A Bacia de Camamu entra nesse contexto como sendo considerada de "nova fronteira".

Brasil, tem sua gênese em contexto tectônico distensivo e por tanto apresentam fases bastante similares de sedimentação variando a duração e época de cada fase (pré-rifte, rifte, transicional e drifte).

As bacias de margem passiva no leste do Este trabalho foca a análise durante a fase 
rifte, para isso seguiu-se os princípios da estratigrafia de sequencias aplicados à Bacias Rifte, preconizado por Prosser (1993) e posteriormente readaptado por Holz et al. (2015);
Gawthorpe \& Leeder, 2000) (Figura 1).

A sismoestratigrafia e a análise de dados de poços através dos perfis de raio gama permitiram aplicar tais princípios.

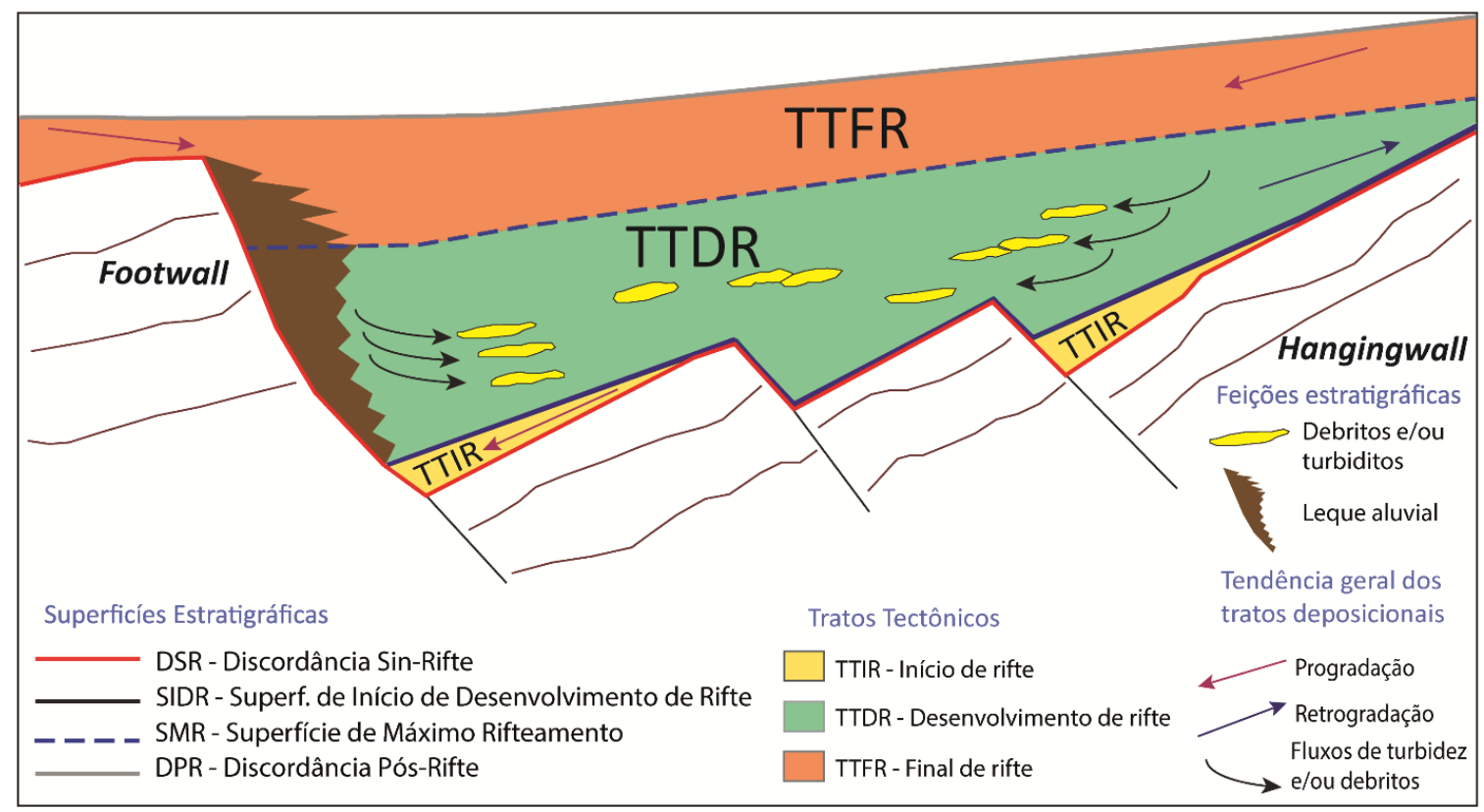

Figura 1 - Modelo estratigráfico para um sistema de meio-gráben de bacia rifte, modificado de Holz et al. (2015).

\section{ESTRATIGRAFIA DE SEQUÊNCIAS APLICADA A BACIAS RIFTE}

A estratigrafia de sequências visa a compreensão dos fatores que influenciam na sedimentação (clima, tectônica e eustasia), e assim, descrever a história de deposição dos estratos rochosos presentes numa região. A estratigrafia resulta em um arcabouço temporal de alta resolução e permite a reconstrução da história deposicional e da subsidência da bacia, desta forma pode fazer predições quanto à exploração/explotação de hidrocarbonetos. Para bacias rifte, no entanto, é preciso considerar as adaptações propostas explicitadas a seguir.

$\mathrm{O}$ rifteamento começa com falhas incipientes que originam pequenas bacias localizadas que conforme vão se desenvolvendo, vão criando espaço de deposição e favorecendo a entrada de sedimentos conforme a inclinação do hangingwall aumenta.

Acontece que as falhas se desenvolvem por pulsos tectônicos que também vão influenciar na sedimentação próxima ao footwall através de depósitos de fluxos como leques aluviais. Os tratos tectônicos são estabelecidos de acordo com a criação de espaço (atividade tectônica).

O Trato de Sistemas Tectônico de Início de Rifte (TTIR) ocorre no início do estiramento crustal, as falhas começam a se instalar, porém ainda sem grandes rejeitos e consequentemente sem gradientes altos em direção às falhas, com a sedimentação dominantemente fluvial. Resultando em um espaço facilmente preenchido pelo aporte sedimentar, resultando assim numa geometria estratal progradante. A superfície que delimita a base desse trato é a Discordância Sin Rifte. O Trato de Sistemas Tectônico de Desenvolvimento de Rifte (TTDR) é o momento tectonicamente mais ativo, as falhas se conectam e há uma maior criação de espaço superando $o$ aporte sedimentar resultando numa geometria estratal retrogradante. A sedimentação é caracteristicamente flúviodeltaica na região proximal do hangingwall, enquanto que no footwall ocorre agradação de sistemas de leques aluviais e a maior parte da bacia se encontra afogada, portanto prepon-derando sedimentação lacustre. $\mathrm{O}$ final desse estágio é o momento de máxima expansão do lago e é marcado por uma superfície lamosa chamada de SMR (Superfície de máximo rifteamento), correlacionável com a STM (Superfície de transgressão máxima) da estratigrafia de sequencias clássica. A superfície que delimita o trato tectônico de início de rifte com TTDR é a SIDR que é caracterizada por uma mudança no padrão progradacional pra retrogradacional nos poços e downlaps nas seções sísmicas.

O Trato de Sistemas Tectônico de Final de Rifte (TTFR) marca o final da tectônica bem ativa do rifte e o aporte sedimentar volta a ganhar 
força e começa a progradar novamente. Com o rebaixamento do relevo, espera-se também que não tenha mais ocorrência de deposição de leques aluviais.

\section{ÁREA DE ESTUDO / BANCO DE DADOS}

A área de estudo está inserida na Bacia de Camamu, a qual situa-se na porção sul do litoral do estado da Bahia aproximadamente entre as latitudes $13,2^{\circ}$ e $14,1^{\circ}$. A área de estudo está inserida na bacia de Camamu, a qual situa-se na porção sul do litoral do estado da Bahia aproximadamente entre as latitudes $13,2^{\circ}$ e $14,1^{\circ}$.

A Bacia de Camamu-Almada está inserida na Margem Leste Brasileira e representa um exemplo típico de margem passiva que teve sua gênese associada à ruptura do supercontinente Gondwana e a consequente abertura do Oceano Atlântico.

Este artigo está inserido no contexto de um projeto maior denominado: "RECAMU Reavaliação da seção rifte da Bacia de Camamu sob a óptica da estratigrafia de sequências e com o apoio da sismoestratigrafia e análise correlativa e comparativa com o setor sul da Bacia do Recôncavo". As seções sísmicas e perfis adquiridos junto ao projeto também foram disponibilizados aos alunos de mestrado e graduação em geologia e geofísica do GETAUFBA (Grupo de Estratigrafia Teórica e Aplicada da Universidade Federal da Bahia). O presente trabalho utilizou da interpretação de dados de 21 poços e 91 linhas sísmicas pósempilhadas de ordem pública (Figura 2).

Os dados de poços adquiridos incluíam perfis geofísicos, arquivos gerais de poços com as informações de perfilagens, coordenadas geográficas, descrições de amostras de calha e etc. Os dados sísmicos adquiridos estavam em formato SEG-Y (padrão da Society of Exploration Geophysics).

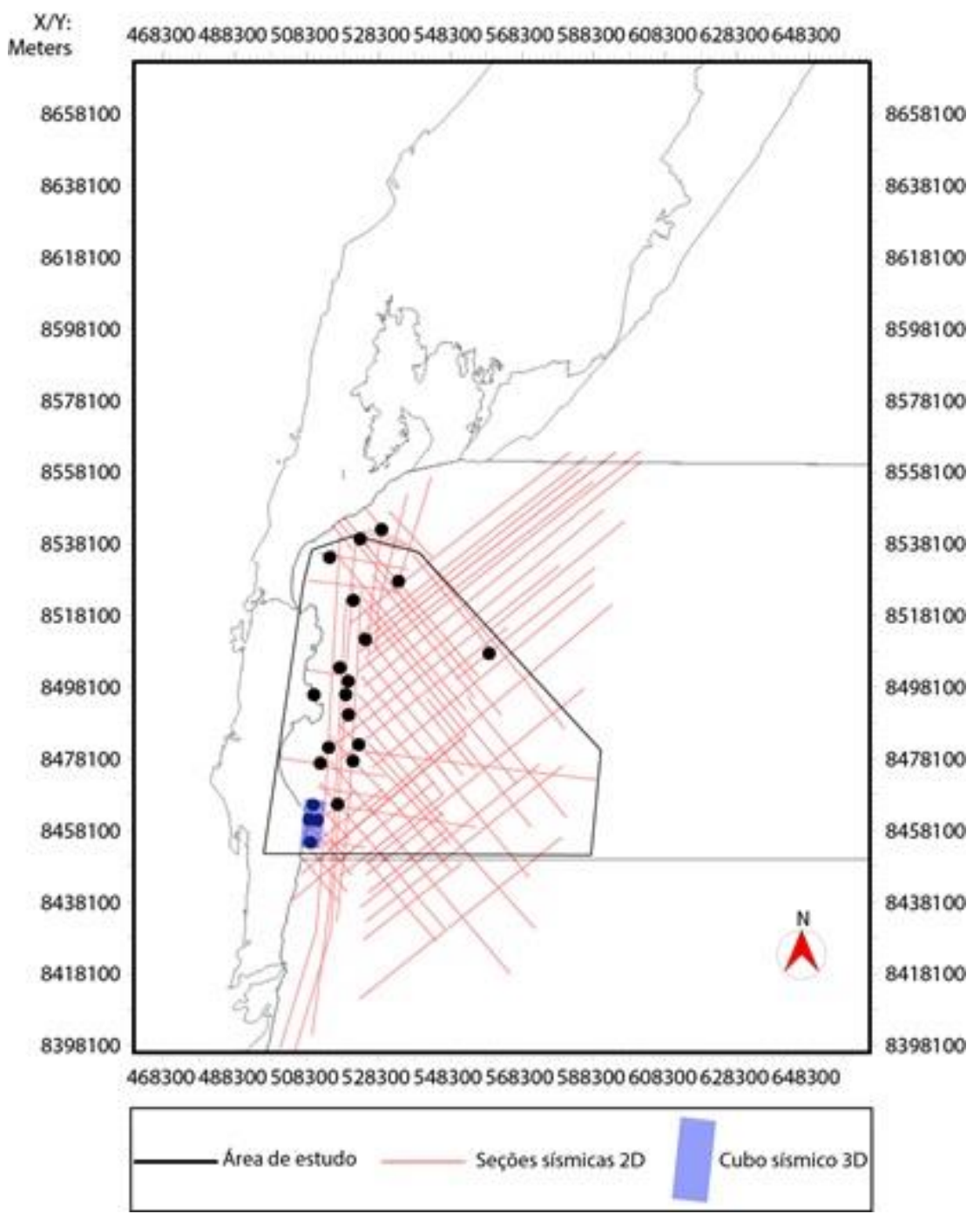

Figura 2 - Banco de dados utilizado para este trabalho. Para a interpretação sismoestratigráfica contou-se com 91 seções sísmicas (2D) e 21 dados de poços perfilados. O cubo sísmico 3D assegurou uma boa qualidade na amarração dos poços nele inserido. 


\section{METODOLOGIA}

Para carregamento dos dados verificou-se no header se este estava de acordo com o default de leitura do software de forma a garantir a leitura correta das informações de localização, datum, cdps e etc. Os softwares utilizados para o carregamento dos dados sísmicos e de poços foram o IHS Kingdom e o OpendTect.

Os perfis geofísicos fornecem informações diretas em subsuperfície que permitem inferir ou mensurar, propriedades físicas das rochas além de caracterizar superfícies ou marcos estratigráficos que podem ser essenciais na análise dos tratos tectônicos das sequências deposicionais.

Para identificar os tratos tectônicos e compreender os possíveis ambientes deposicionais foram identificadas (quando possível) as superfícies DSR, SIDR e SMR utilizando o perfil de raio gama. A figura 3 mostra um exemplo de interpretação.

Para análise sismoestratigráfica, as seções sísmicas foram interpretadas em amplitude, com filtragens quando preciso, e atributos sísmicos de Pseudo-Relief para interpretação estrutural e fase instantânea para melhor visualização de termi- nações estratais. Para correlação entre os dados sísmicos e de poços, foram gerados sismogramas sintéticos a partir das curvas de densidade e sônico. Para a amarração poçosísmica, curvas foram editadas de modos a retirar valores incoerentes e seguiu-se um passo-a-passo de forma a obter o máximo de precisão na $T D$-Chart, obtenção da wavelet $\mathrm{e}$ modelo de refletividade. Os poços inseridos no perímetro do cubo sísmico, tiveram melhores coeficientes de amarração devido à maior amostragem na obtenção da wavelet extraída do dado sísmico.

Os dados culturais são utilizados para trazer às interpretações informações de diferentes tipos de mapas retirados da literatura. Para este trabalho, foram carregados, mapas estruturais, geográficos, litológicos, gravimétricos e mapas sísmicos. É preciso garantir que o mapa esteja na posição correta, para isso o georreferenciamento foi realizado através do Software ArcGis.

Como exemplo de mapas bastante utilizados estão os gravimétricos e estruturais dos trabalhos de Ferreira et al. (2009) e Destro et al. (2003).

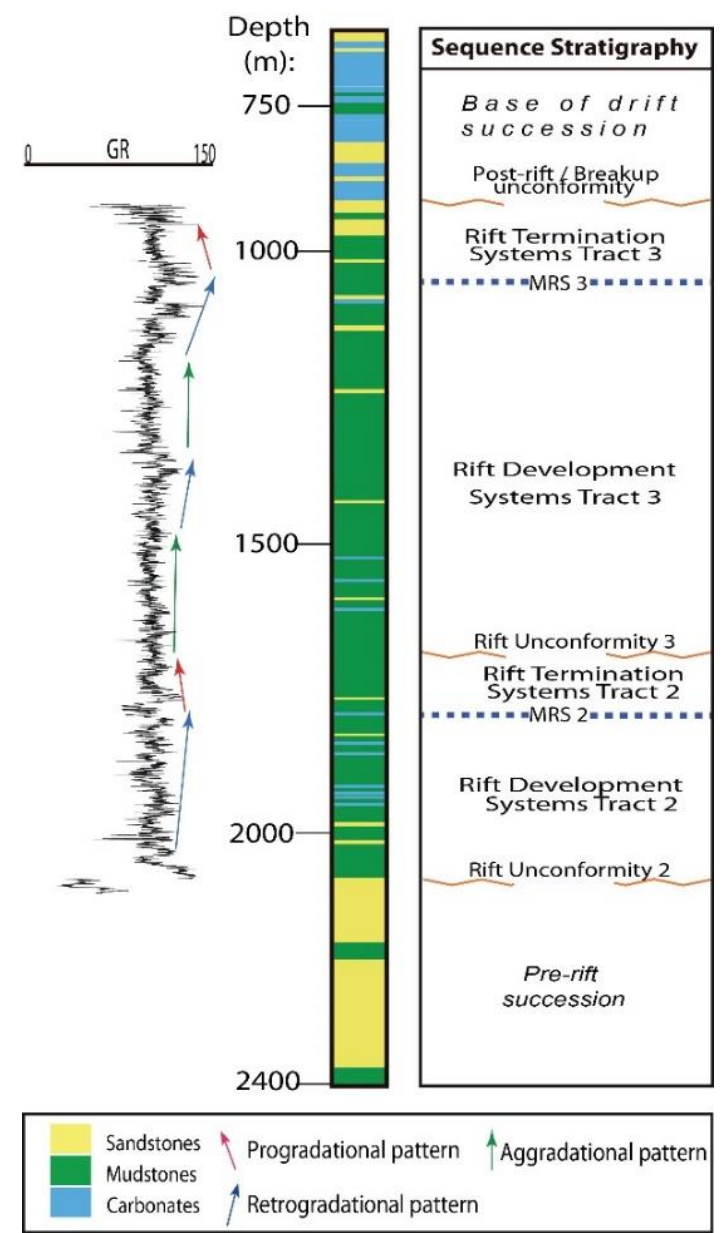

Figura 3. Leitura do perfil de raio gama e os padrões de sedimentação utilizados para a determinação de superfícies que delimitam os tratos tectônicos. 


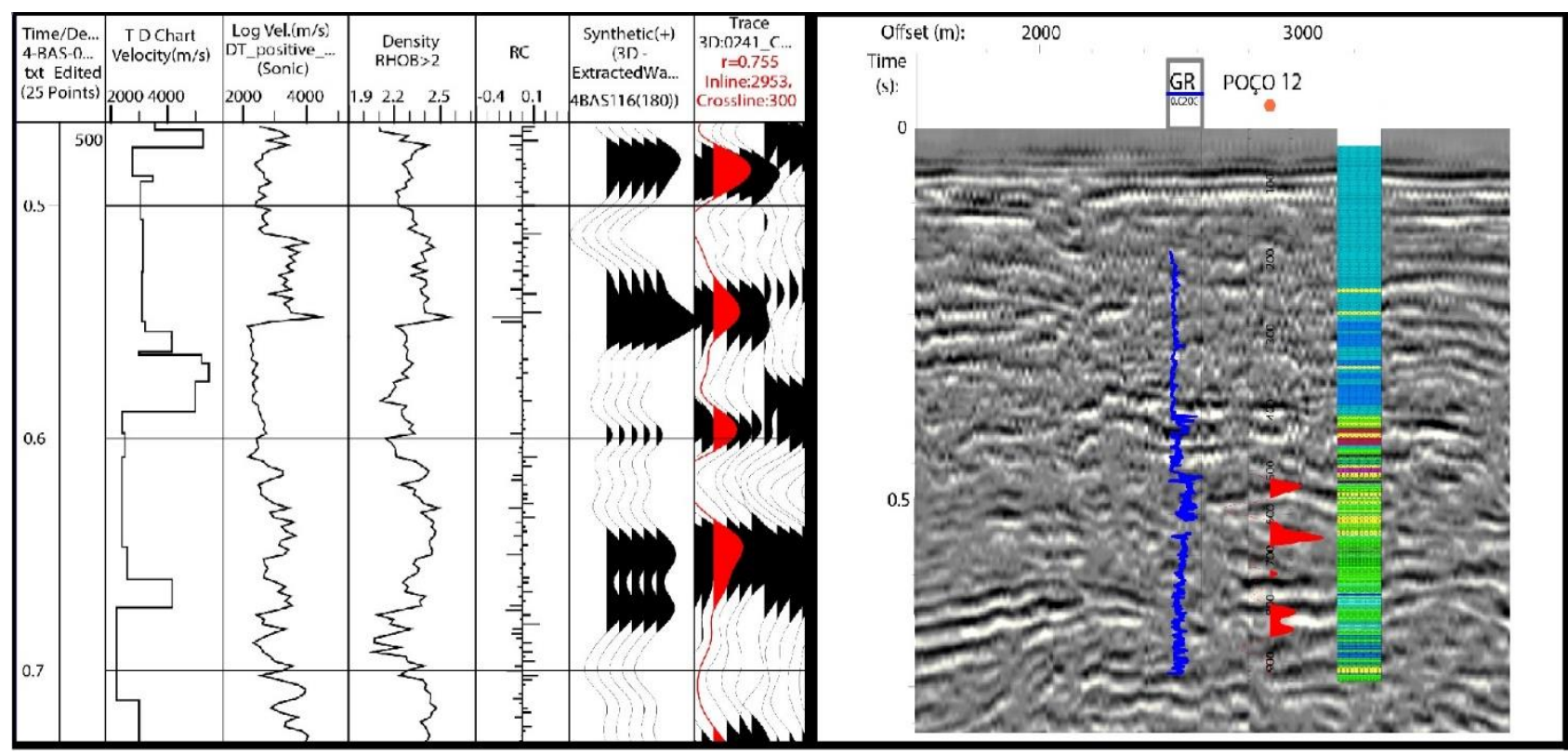

Figura 4. Painel de correlação sísmica-poço, e a amarração resultante na seção sísmica. O coeficiente de correlação para este poço é de 0.755 .

\section{ANÁLISE SISMOESTRATIGRÁFICA}

Cinco sequências deposicionais de terceira ordem foram mapeadas na fase rifte do sul da Bacia de Camamu. A área proximal conta com a maior parte dos poços e estes são correlacionáveis com as principais seções sísmicas.

Para a área distal, está o maior montante de

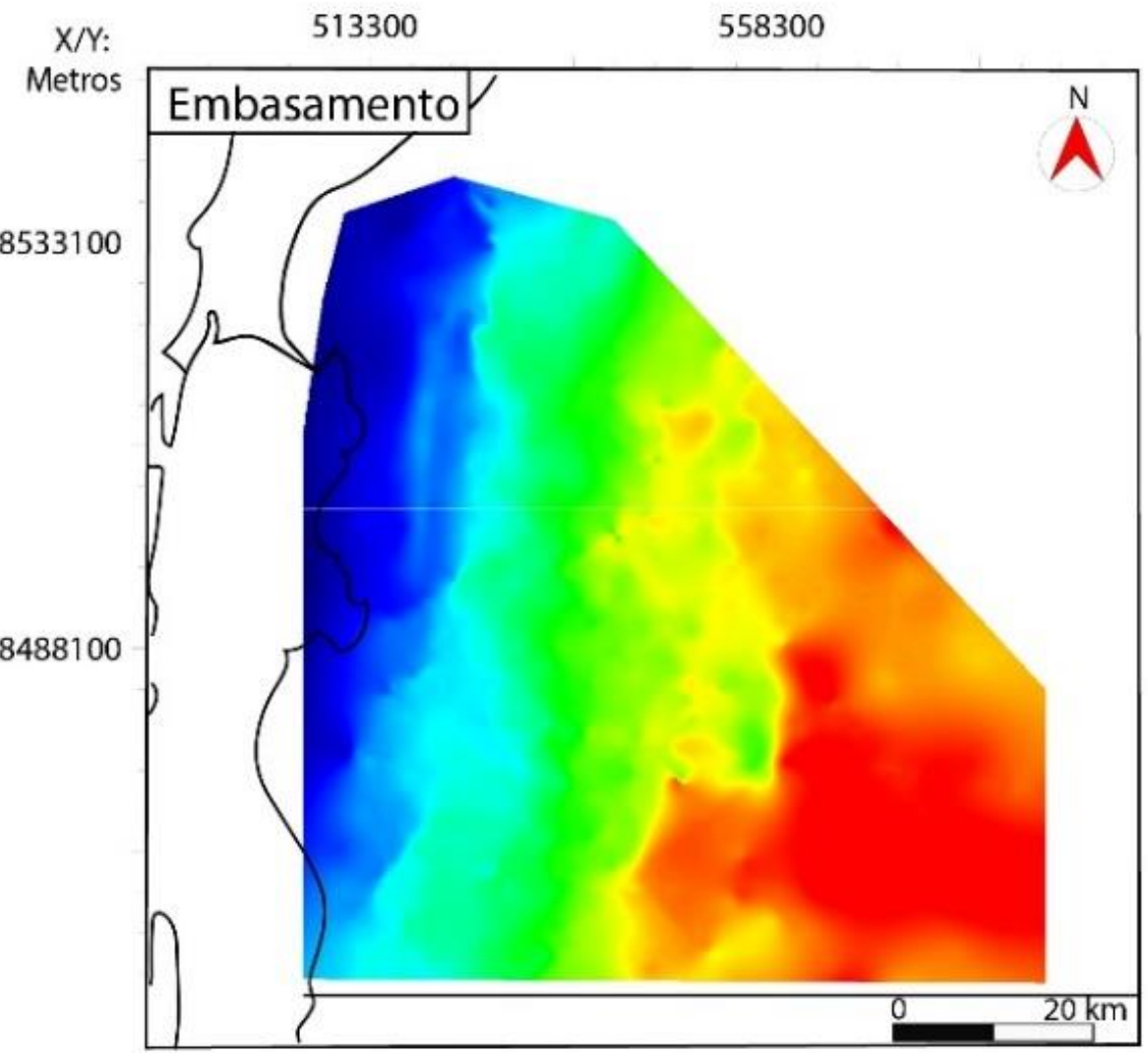

dados sísmicos, porém com apenas um poço correlacionável.

\section{Embasamento e Pré-rifte}

O embasamento é sobreposto por depósitos da fase de sinéclise e posteriormente da fase prérifte e seu mapeamento engloba toda a área de estudo (Figura 5).

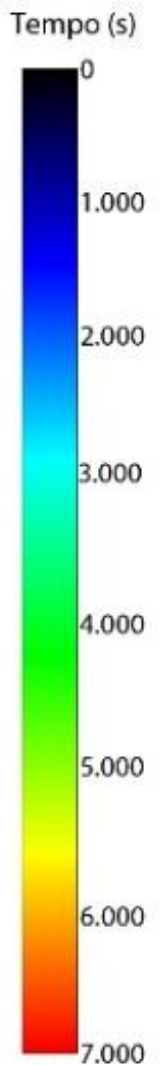

Figura 5: Mapa de isócronas do embasamento na área de estudo. Notar alto no centro da figura que corresponde a uma falha normal com mais de $2 \mathrm{~s}$ de tempo sísmico de rejeito. 
O limite superior dessa sequência é a Discordância DR-1, que litoestratigraficamente coincide nos poços com o contato entre a formação Sergi com o a formação Itaípe. O Sergi possui um padrão de assinatura do raio gama característico em formato de caixa, de maneira que o contato é em grande parte dos casos abrupto e facilmente identificável.
O limite inferior é o contato com o embasamento cristalino e os poços da área de estudo não chegam a atingi-lo.

O mapeamento do embasamento nas regiões proximais tem boa confiabilidade devido ao término do padrão característico da sequência pré-rifte na região em contato como padrão de sismofácies caótica abaixo (Figura 1Figura 6).

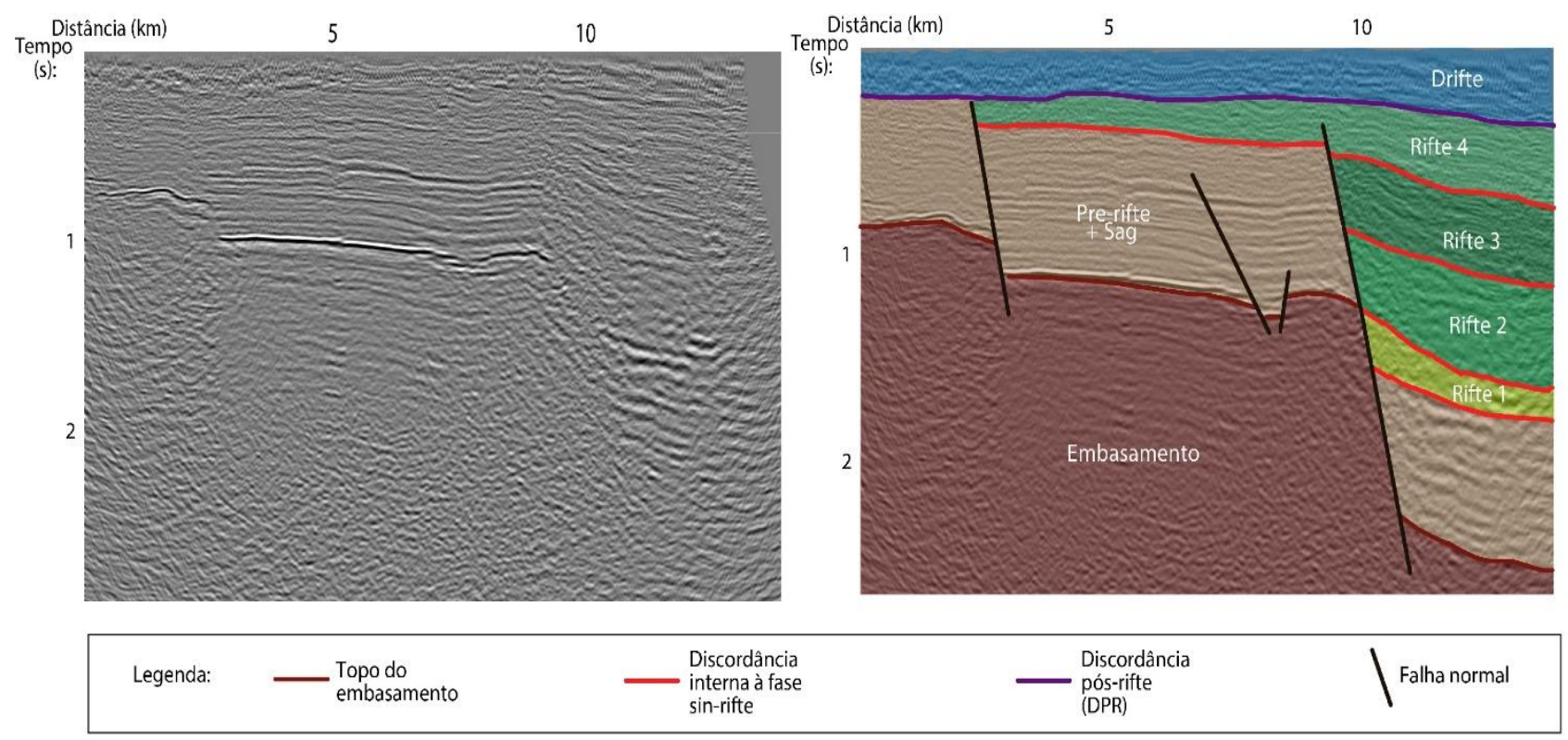

Figura 6 - Seção sísmica localizada na região proximal com exemplo da diferença de sismofácies entre embasamento, pré-rifte e rifte.

A sequência pré-rifte possui geralmente sismofácies características com refletores de alta amplitude, boa continuidade e media frequência. Nas regiões proximais, a sua mudança de fácies entre os depósitos do estágio rifte e pré-rifte são bastante claros.

Para a região distal, costuma apresentar ainda uma diferença de fácies sísmicas, que evidencia essa diferença de ambiente deposicional entre flúvio-eólico e lacustre, porém a configuração interna pode ser do tipo divergente, que neste caso seria devido à efeito de compactação diferencial (Veeken, 2007; Veeken, \& Moerkerken, 2013; Santos \& Amorim, 2005.)

A espessura sísmica da sequência pré-rifte varia pouco, estando entre $500 \mathrm{~ms}$ e $800 \mathrm{~ms}$ e seu mapeamento foi possível em toda a área de estudo com boa confiabilidade nas regiões proximais devido à boa continuidade dos refletores.

Poços interpretados foram amarrados à sísmica e auxiliaram na marcação do limite superior (DR-1).

A sequência pré-rifte não apresenta evidências de atividade tectônica sin- deposicional, apesar de bastante falhada devido à alta atividade durante fase rifte.

\section{Sequência Rifte 1}

Esta sequência representa os primeiros lagos a se formarem no início do rifteamento da bacia. As falhas são incipientes e formam-se lagos isolados com sedimentação predominantemente lacustre.

Os poços, como o mostrado na Figura 7 evidenciam uma diferença na resposta do raio gama muito grande em relação à sedimentação pré-rifte que conota uma mudança significativa de sistema deposicional.

Nota-se também que nesse contexto há pouca ou nenhuma formação de leques ou fluxos gravitacionais, possivelmente devido ao tectonismo pouco intenso dessa fase.

Não foi possível fazer a análise de tratos de sistemas para o Rifte 1 possivelmente devido à ser muito delgada para tal análise, além de na região proximal, poder ter tido as superfícies limítrofes dos tratos (SIDR e SMR) erodidas pela DR-2. Sismicamente na parte distal tampouco foi possível marcar alguma superfície interna devido à resolução sísmica. 


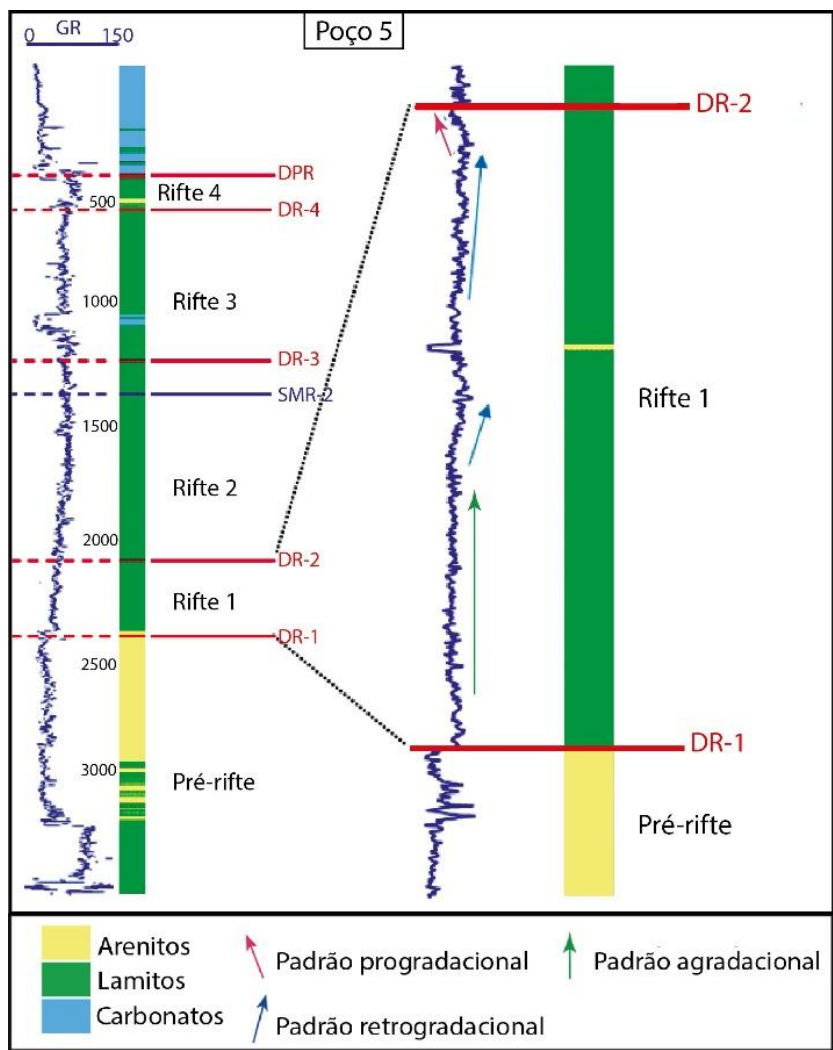

Figura 7 - Poço interpretado com destaque para a Sequência Rifte 1.

Esta sequência apresenta espessura menores que $100 \mathrm{~ms}$ em grande parte do Sul de Camamu, a Figura 8 mostra estratos de crescimento que evidenciam alguma atividade tectônica e a diferencia da fase pré-rifte. A direção das falhas mapeadas sismicamente e com auxílio do mapa Bouguer, estão preferencialmente para NNWSSE na região central e NNE-SSW já próximo ao limite da Bacia com Almada, aproximadamente paralelas a atual costa.

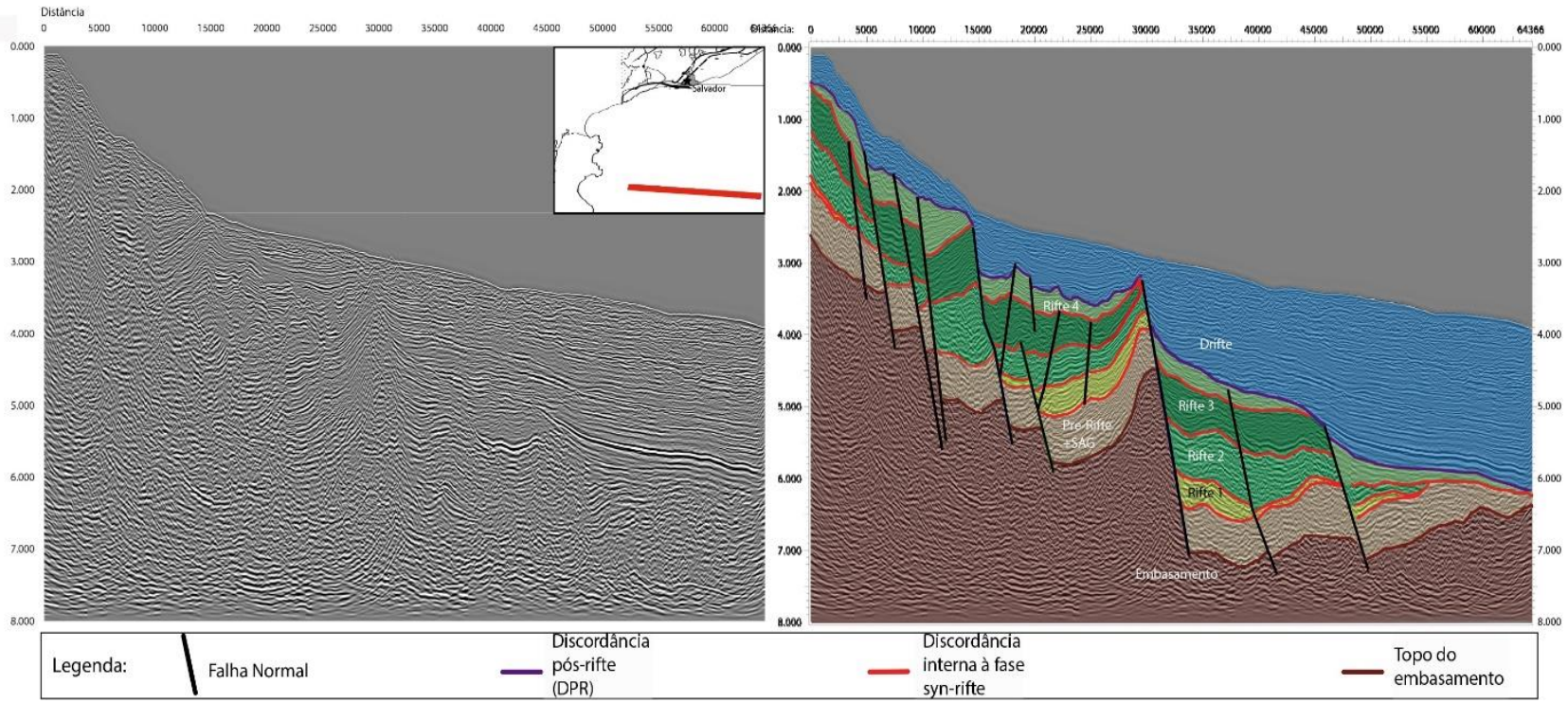

Figura 8 -Seção sísmica dip representativa do sul da Bacia de Camamu. Notar a falha normal que situa-se no centro da área de estudo.

Esta sequência apresenta espessura menores que $100 \mathrm{~ms}$ em grande parte do Sul de Camamu, a Figura 8 mostra estratos de crescimento que evidenciam alguma atividade tectônica e a diferencia da fase pré-rifte. A direção das falhas mapeadas sismicamente e com auxílio do mapa
Bouguer, estão preferencialmente para NNWSSE na região central e NNE-SSW já próximo ao limite da Bacia com Almada, aproxima-damente paralelas a atual costa.

$\mathrm{Na}$ análise de fácies sísmicas, o rifte 1 possui basicamente duas fácies sísmicas características. 
A primeira apresenta refletores que variam de média a alta amplitude e de baixa a média frequência e está associada a um ambiente deposicional sob um contexto de lenta criação de espaço em relação ao TTDR, onde os sistemas fluviais se intercalam com o sistema lacustre, causando contrastes de litologia-densidade. A segunda sismofácies tem baixa amplitude, baixa continuidade e caráter mais caótico e está associada a depósitos predominantemente lacustres que possivelmente devido à sua característica reológica plástica, são facilmente deformáveis.

\section{Sequência Rifte 2}

A sequência rifte 2 representa um lago que ocupa quase toda a área de estudo com alta atividade tectônica e litoestratigraficamente é correlacionável com a Formação Morro do Barro.

Os perfis de raio gama juntamente com as descrições litológicas permitiram a marcação da SMR-2, delimitando assim o TTDR-2 e o TTFR2. Dessa forma fez-se possível a confecção de mapas de espessura desses tratos para a região proximal da área de estudo, local onde se concentram os poços. A Figura 9 é um exemplo do mapeamento da SMR-2, que foi correlacionada sismicamente graças à amarração de poços.

A confecção dos mapas de espessuras sísmicas dos tratos tectônicos evidenciou a alta atividade tectônica no TTDR-2. A taxa de criação de espaço nesta sequência ocorreu com intensidade alta o suficiente para que o TTIR-2 que teria um padrão progradacional, não possuísse espessura expressiva. A figura 10 mostra lado a lado o TTDR-2 e o TTFR-2 e notase quatro principais depocentros. Um destes é uma anomalia a norte que possui menor expressividade devido à erosão de seus depósitos por canais que foram mapeados sismicamente. A SMR-2 no local possui formato ligeiramente antiforme e pode caracterizar uma possível trapa de hidrocarbonetos já que poços perfilados próximos a essa região constataram evidências de óleo e gás da Formação Morro do Barro. Falhas, estratos de crescimento e fluxos gravitacionais corroboram para o fato de haver ocorrido intenso tectonismo na região que parece não ter agido durante a deposição do rifte 1 . Um exemplo associado a fluxos gravitacionais associado a um período de alto tectonismo pode ser visto na seção geológica de poços 1 (Figura 21).

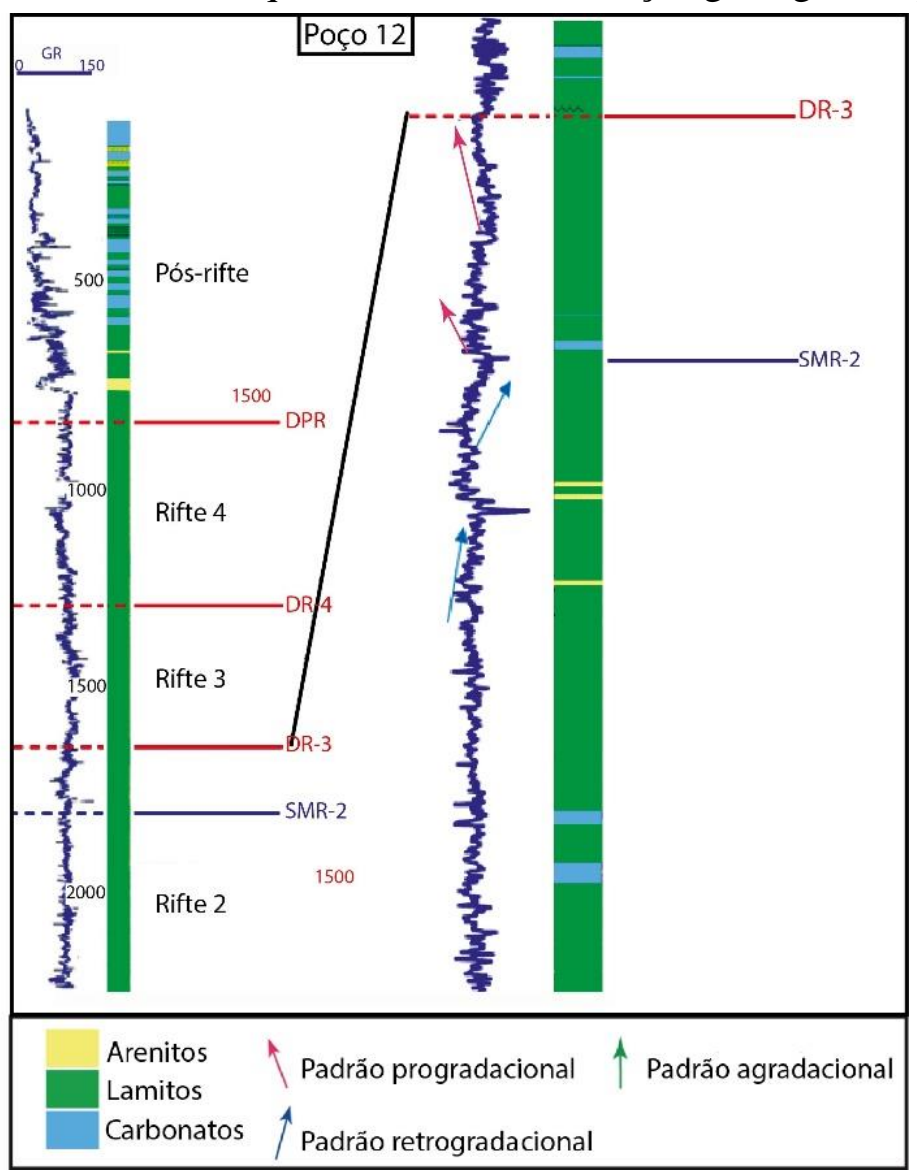

Figura 9 - Poço interpretado com destaque para a SMR-2 que delimita o TTDR do TTFR. Notar o padrão retrogradacional da curva de raios gama até atingir o pico na SMR-2 dando início a um padrão preferencialmente progradacional. 


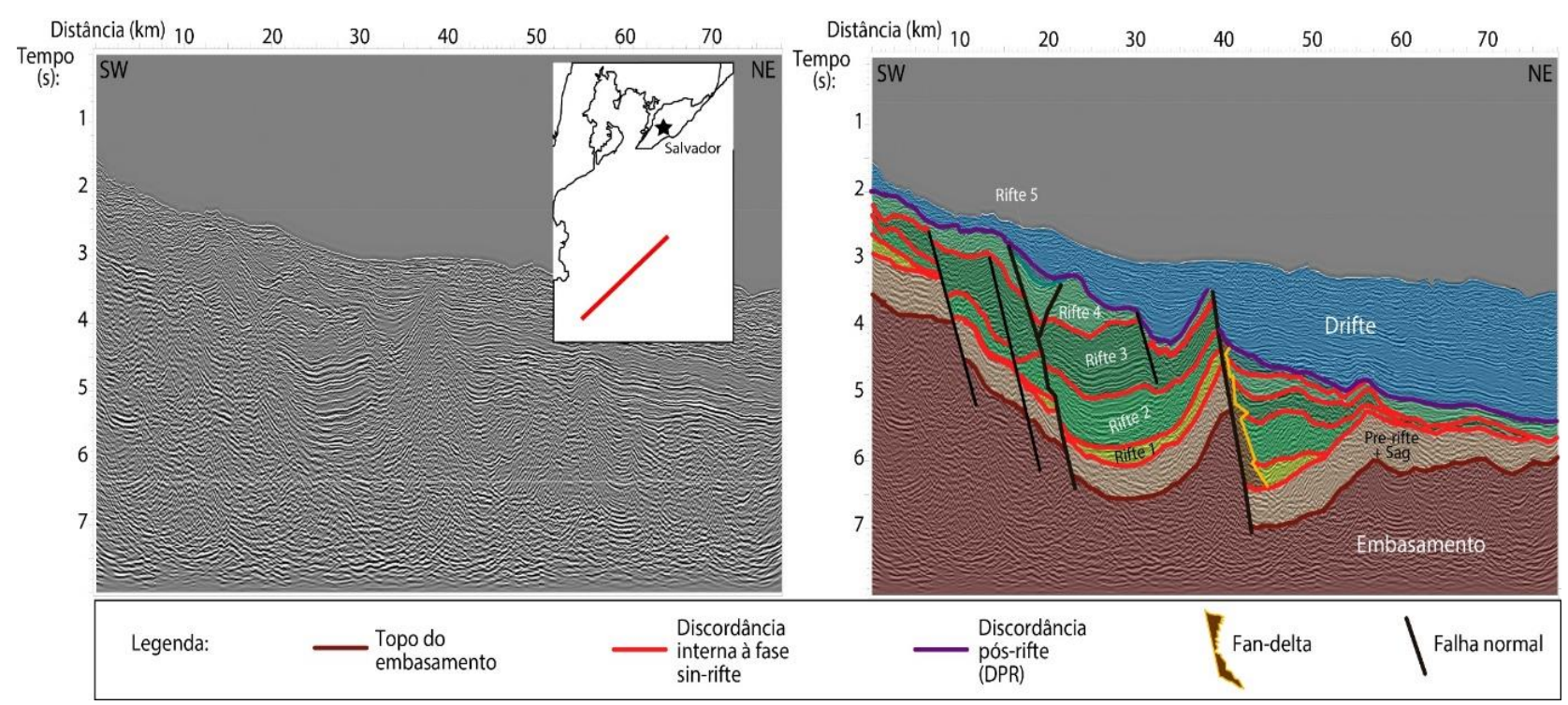

Figura 10 - Mapa de espessuras sísmicas dos tratos tectônicos da Sequência Rifte 2 na região proximal. Devido à intensa atividade tectônica dessa área nesse período, é possível notar o lineamento das falhas no mapa TTDR-2.

Essa sequência apresenta como fácies sísmicas na região proximal, refletores com comportamento caótico e com estratos de crescimento de baixa continuidade e amplitude variando de alta a baixa. Isso se deve à alta atividade tectônica nessa região que favoreceu a criação de espaço de acomodação e sedimentação lacustre com ocorrência de fluxos gravitacionais. $\mathrm{Na}$ seção sísmica da figura 11 veem-se também leques aluviais interpretados na borda da falha sobre o padrão de sismofácies caótico. A maior criação de espaço é evidenciada na região proximal com a evolução das falhas do rifte 1 além do surgimento de novas falhas. $\mathrm{Na}$ região distal também há indícios de tectonismo e criação de espaço, apenas um pouco menos intenso que na região proximal.

A espessura dessa sequência chega a ultrapassar 1000 ms e devido à deposição syntectônica evidenciada também por estratos de crescimento, esta sequência possui espessuras muito variáveis.

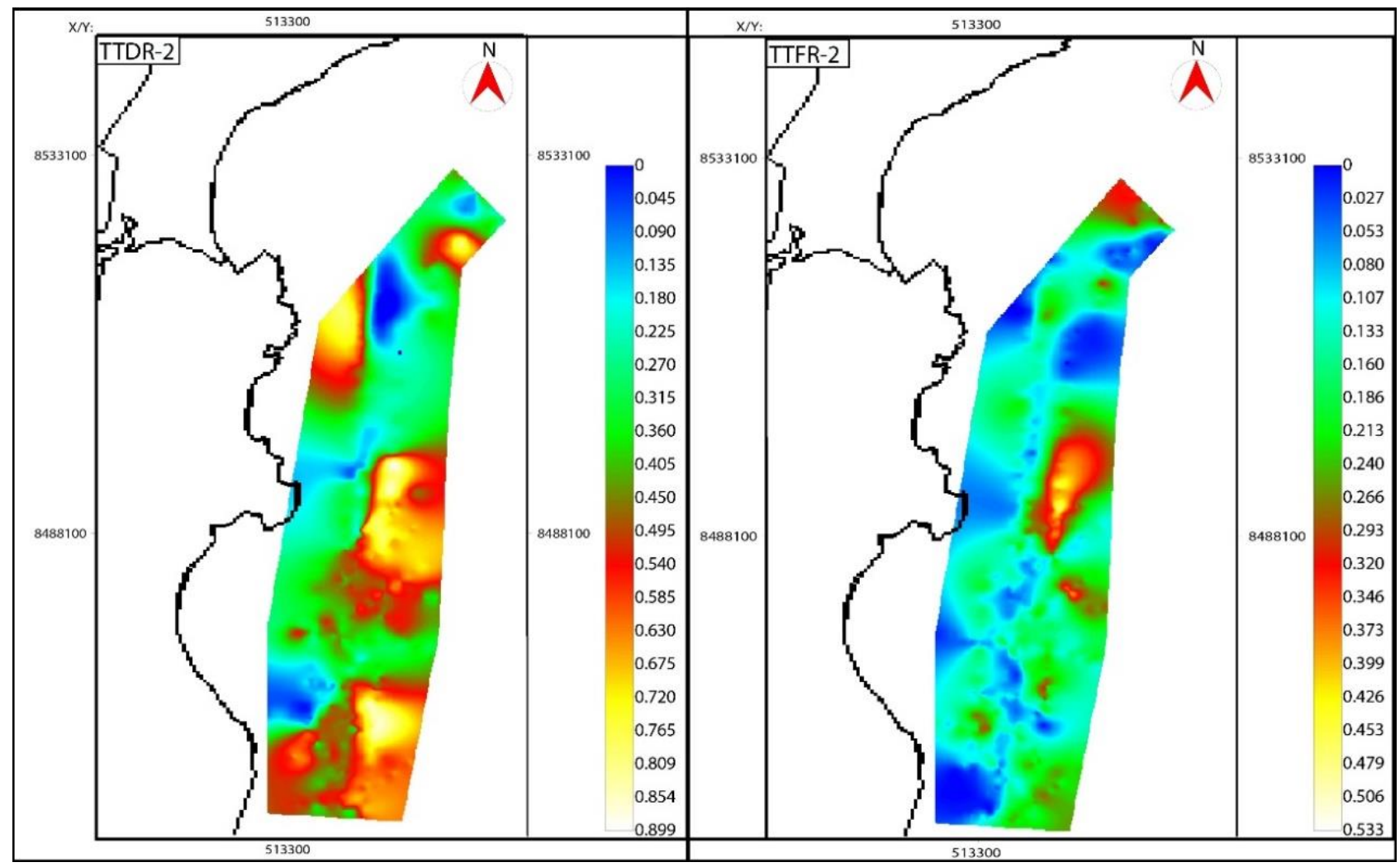

Figura 11 - Seção sísmica strike representativa do sul da Bacia de Camamu. O Rifte 2 apresenta estratos de crescimento evidenciando atividade sin-tectônica. 


\section{Sequência Rifte 3}

O rifte 3 , assim como o 2 , está em um contexto de expansão do lago. O lago continua ocupando grande parte da área de estudo com a diferença que o a atividade tectônica agora é maior nas porções distais.

Litoestratigraficamente os depósitos dessa sequência são correlacionados com os depósitos da Formação Rio de Contas com exceção de dois poços onde estariam associados à Formação Morro do Barro. O estudo de tratos de sistemas foi possível de ser realizado na região proximal da bacia devido ao grande número de poços amarrados que atingiam essa sequência.

A superfície DR4 que limita o topo dessa sequência deposicional de terceira ordem é mapeável principalmente por truncamentos sísmicos, apesar de haver indícios em alguns poços como o da Figura 132, que mostra uma quebra bastante significativa no perfil de raios gama. A fácies sísmicas que predominam no rifte 3 se assemelham à do rifte 2 , já que representam ambientes deposicionais seme-lhantes. No caso do rifte 3, como a maior criação de espaço foi distalmente, sua fácies se assemelha à fácies proximal do rifte 2 , isto é, refletores com comportamento caótico, estratos de crescimento e baixa continuidade com amplitude variada (Figura 13). As fácies sísmicas que predominam no rifte 3 se assemelham à do rifte 2 , já que representam ambientes deposicionais semelhantes.

No caso do rifte 3, como a maior criação de espaço foi distalmente, sua fácies se assemelha à fácies proximal do rifte 2 , isto é, refletores com comportamento caótico, estratos de crescimento e baixa continuidade com amplitude variada.

\section{Sequência Rifte 4}

O Rifte 4 apresenta uma diminuição da extensão e espessura sísmica do lago, representando uma diminuição na atividade tectônica. O rifte 4, é limitado na base pela DR4 que foi mapeado principalmente através da marcação de truncamentos erosivos. A DR5 limita o topo que em grande parte foi erodido pela DPR que foi mapeada regionalmente.

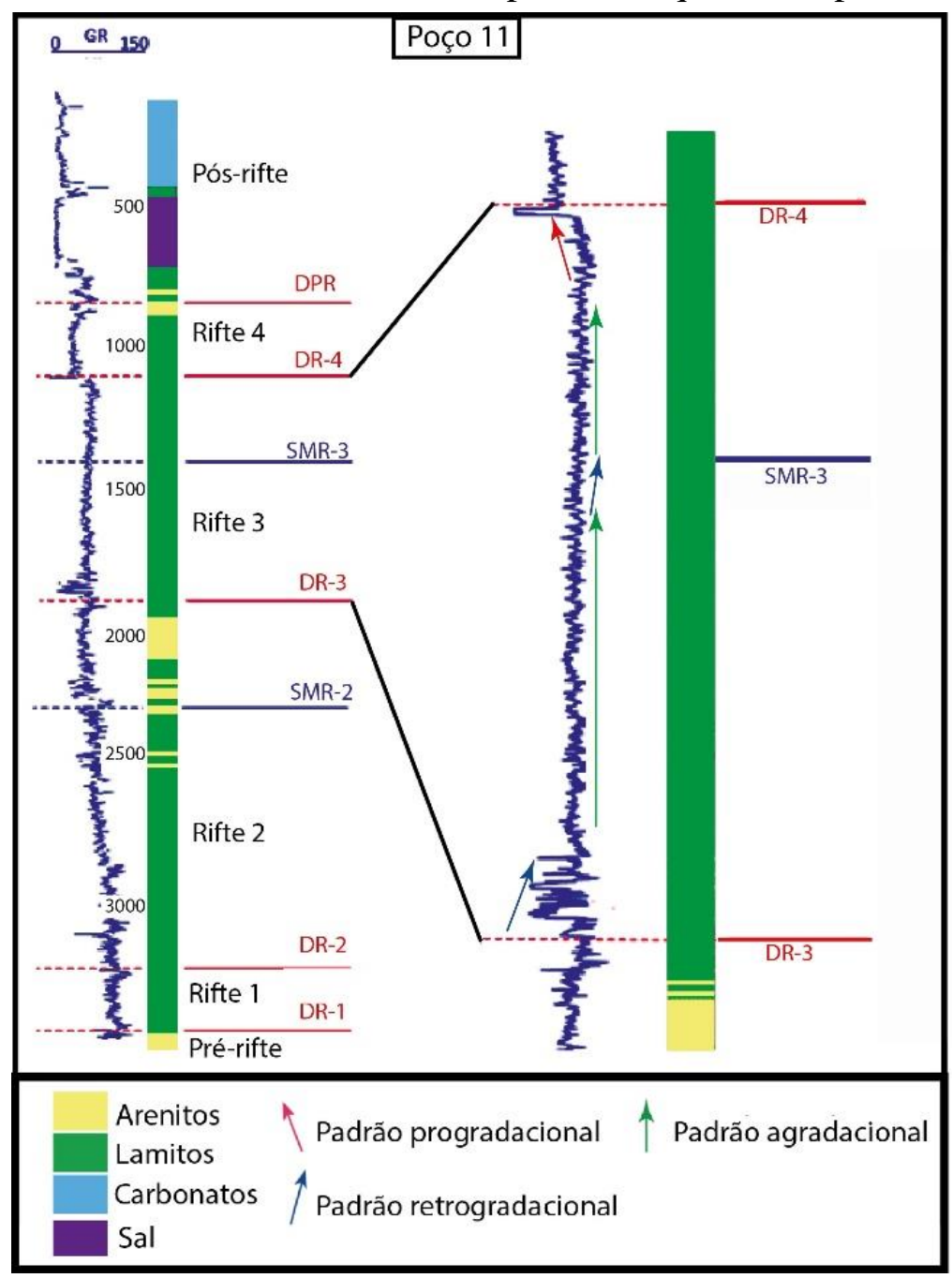

Figura 12 - Poço interpretado evidenciando a identificação da SMR-3, delimitando o TTDR-3 e o TTFR-3. Notar a mudança no padrão retrogradacional para progradacional. 


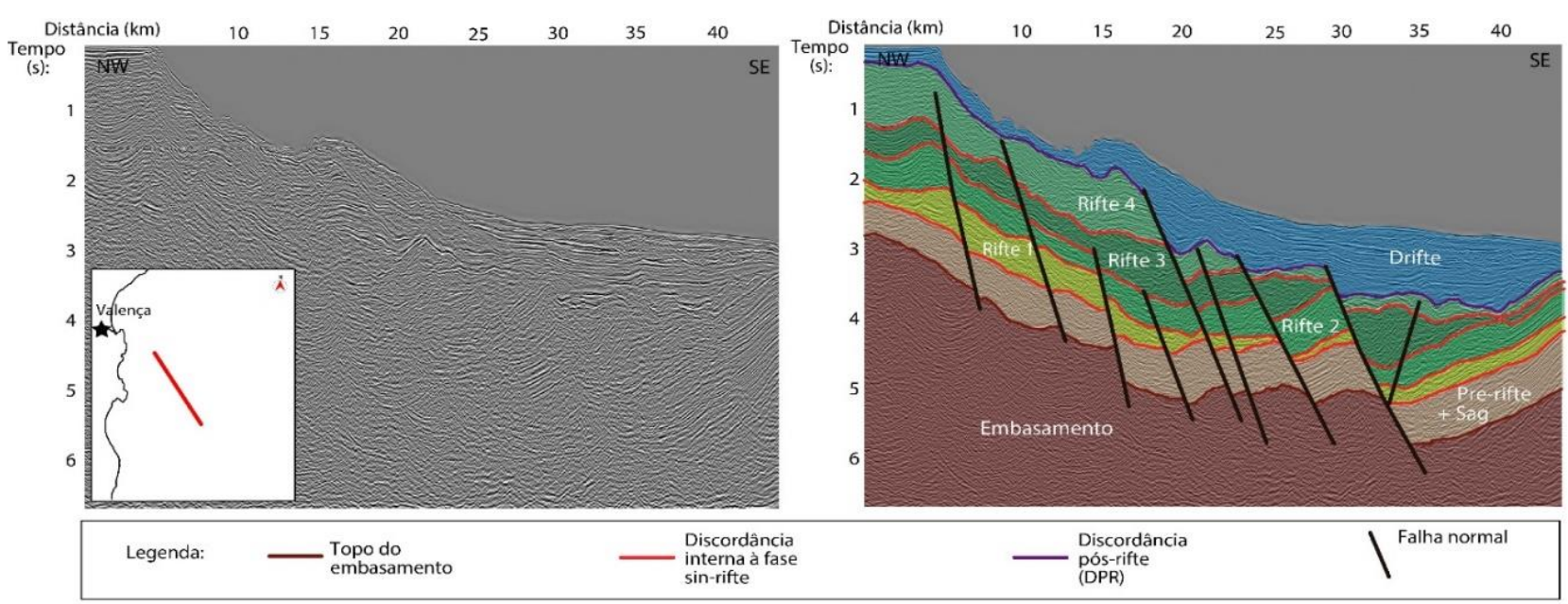

Figura 13 - Seção sísmica representativa da sequência Rifte 3, notar seu espessamento nas regiões mais distais da Bacia.

Essa sequência foi identificada amarrada à A análise de tratos, no entanto, não foi sísmica em diversos poços, como ilustra o possível de ser realizada devido à ausência da exemplo da Figura 14.

SMR na grande maioria dos poços da área.

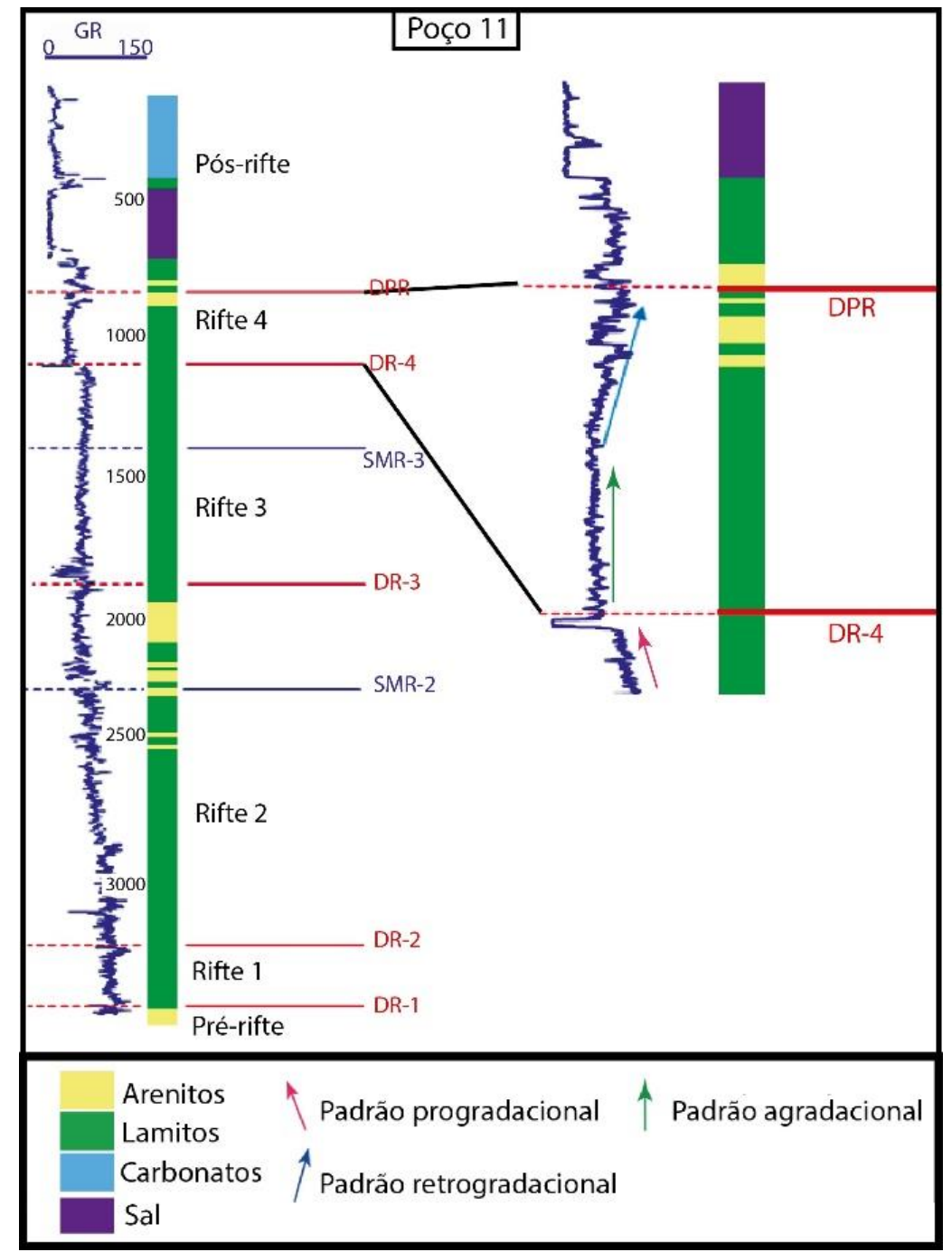

Figura 14 - Poço interpretado representativo da sequência Rifte 4, no qual não foi identificada a SMR-4 devido possivelmente à erosão da mesma pela DPR.

Litoestratigraficamente, esta sequência está apresenta comportamento do perfil raio gama relacionada à Formação Rio de Contas e agradacional a retrogradacional. Em alguns apresenta sedimentação lacustre com poços esta sequência é associada às fácies intercalações de debritos arenosos e turbiditos e lacustres e flúvio-deltaicas da Formação Taipus- 
Mirim.

A seção sísmica representativa dip (Figura 15Figura 14) mostra estratos com alta amplitude, boa continuidade e media frequência.

O caráter plano-paralelo com menor presença de padrões divergentes ou estratos de crescimento, denota uma deposição em um ambiento tectonicamente menos ativo que nos riftes 2 e 3. A maior amplitude dos refletores também denota uma maior intercalação de litologias diferentes, podendo ser associadas a maiores intercalações de folhelho-arenito decorrente de estarem inseridos em um contexto progradacional, onde os sistemas predominantemente lacustres dos riftes 2 e 3 vão dando a espaço a sistemas flúvio-deltaicos.

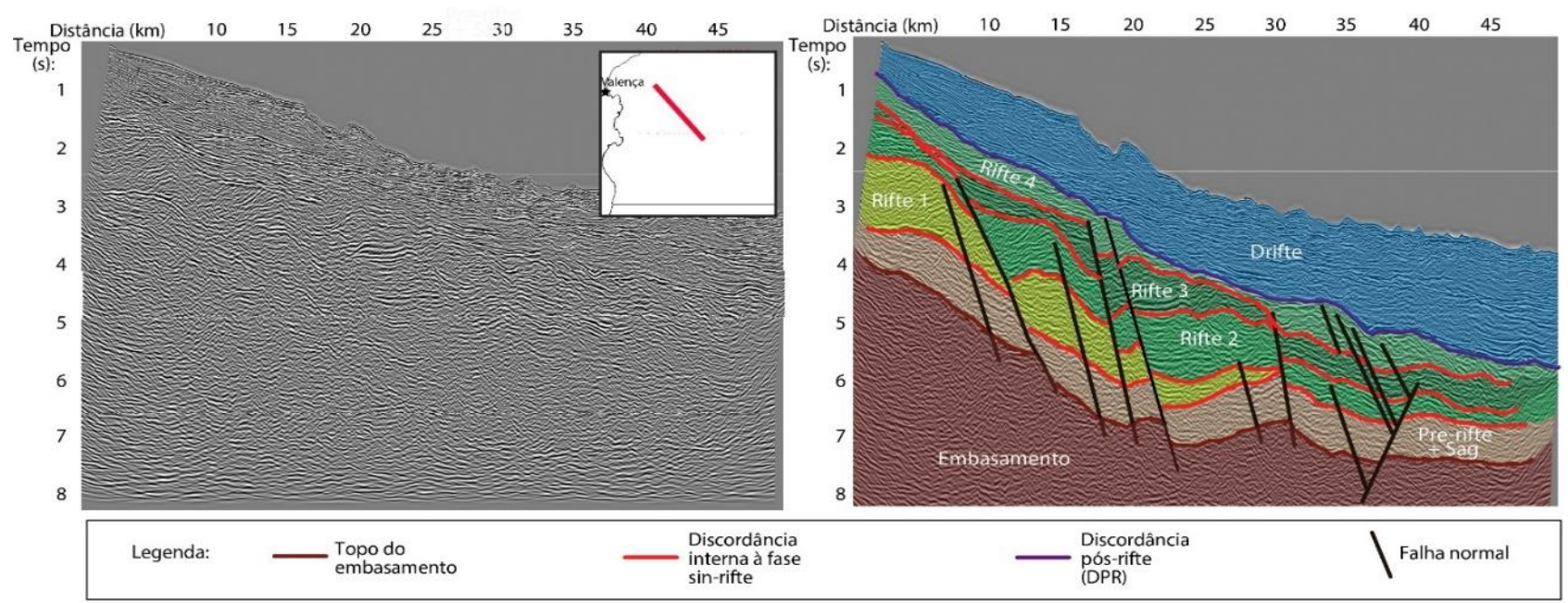

Figura 15 - Seção sísmica representativa da Sequência Rifte 4. Notar como essa sequência quase não possui falhamentos nesta região evidenciando a diminuição tectônica.

\section{Sequência Rifte 5}

$\mathrm{O}$ rifte 5 representa um momento de progradação dos sistemas fluvio deltaicos e recuo dos sistemas deposicionais lacustres. Essa sequência encontra-se localizada em pequenas regiões distais da bacia, por isso não há poços que a representem na área de estudo. Seu contexto tectônico é semelhante ao do rifte 4 . Após a tectônica gradualmente começar a cessar, os depósitos que agora eram depositados se davam por rebaixamento do nível de base devido principalmente a subsidência termal (Figura 16). O rifte 5 é limitado na base pela discordância DR5 e no topo pela discordância DPR. A DR5 é marcada por truncamentos erosivos e sua principal característica na região distal é a presença de onlaps sobre a mesma. $\mathrm{O}$ mapeamento da DPR, no entanto é de grande confiabilidade já que possui truncamentos erosivos bem marcados além de marcar uma mudança de fácies sísmicas em grande parte da área.

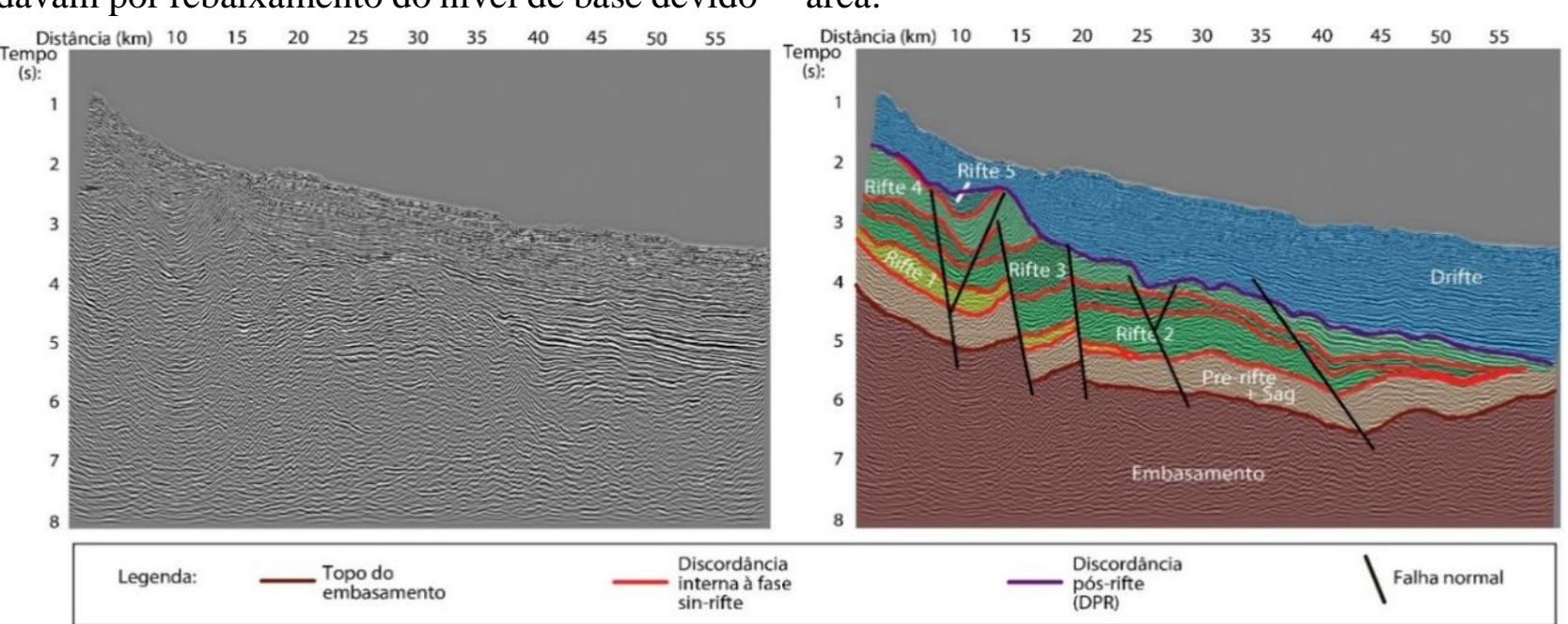

Figura 16 - Seção sísmica dip representativa para o Rifte 5. Notar como os refletores dessa sequência estão dispostos em formato de cuia, seus estratos de crescimento são para seu centro com flancos delgados trazendo uma conotação de deposição sob subsidência térmica. 
$\mathrm{Na}$ análise dos dados de poços não se identificou essa sequência por esta concentrar-se principalmente nas regiões distais onde não há poços. O padrão de fácies sísmica dominante é de media amplitude com refletores com boa continuidade, plano-paralelos, ligeiramente caóticos e com poucos estratos de crescimento. A DPR separa esta fácies para uma de padrão de baixíssima amplitude interna denotando pouca variação litológica ou contraste velocidadedensidade.

\section{Sequência Rifte Total}

Uma sequência deposicional de primeira ordem é relativa ao ciclo de formação e preenchimento de uma bacia ao longo de dezenas ou centenas de milhões de anos, levando a um registro de quilômetros de espessura.

Já uma sequência deposicional de segunda ordem refletem mudanças no padrão tectônico, evidenciado por ciclos de soerguimento e reorganização da bacia em termos de áreas-fonte, limites, direção de aporte sedimentar e clima. As sequências de terceira ordem estão inseridas dentro da supersequência de segunda ordem e contém o registro de variações tectônicas menores, que podem ser mais expressivas em uma borda da bacia do que em outra e serem melhor determinadas em uma área, enquanto em outra pode estar ausente (Holz, 2012).

A Bacia de Camamu desde a sua fase pré-rifte até atualmente na fase drifte esta então associado a um grande evento geológico, a abertura do paleocontinente Gondwana. Dessa forma podemos dizer que a Bacia como um todo, é uma sequência de primeira ordem.

O Rifte Total representa a fase de predomínio da subsidência mecânica ao invés da térmica e é marcada por ser a fase lacustre da bacia. Dessa forma, pode-se dizer que o Rifte Total é a sequência de segunda ordem que envolve as cinco sequências deposicionais de terceira ordem mapeadas e discutidas até então (Rifte 1, 2, 3, 4 e 5). Foi confeccionada uma carta estratigráfica proposta (Figura 17), baseada nas interpretações sismoestratigráficas e por correlações litoestratigráficas através dos dados de poços com as idades propostas na carta de Caixeta et al. (2007).

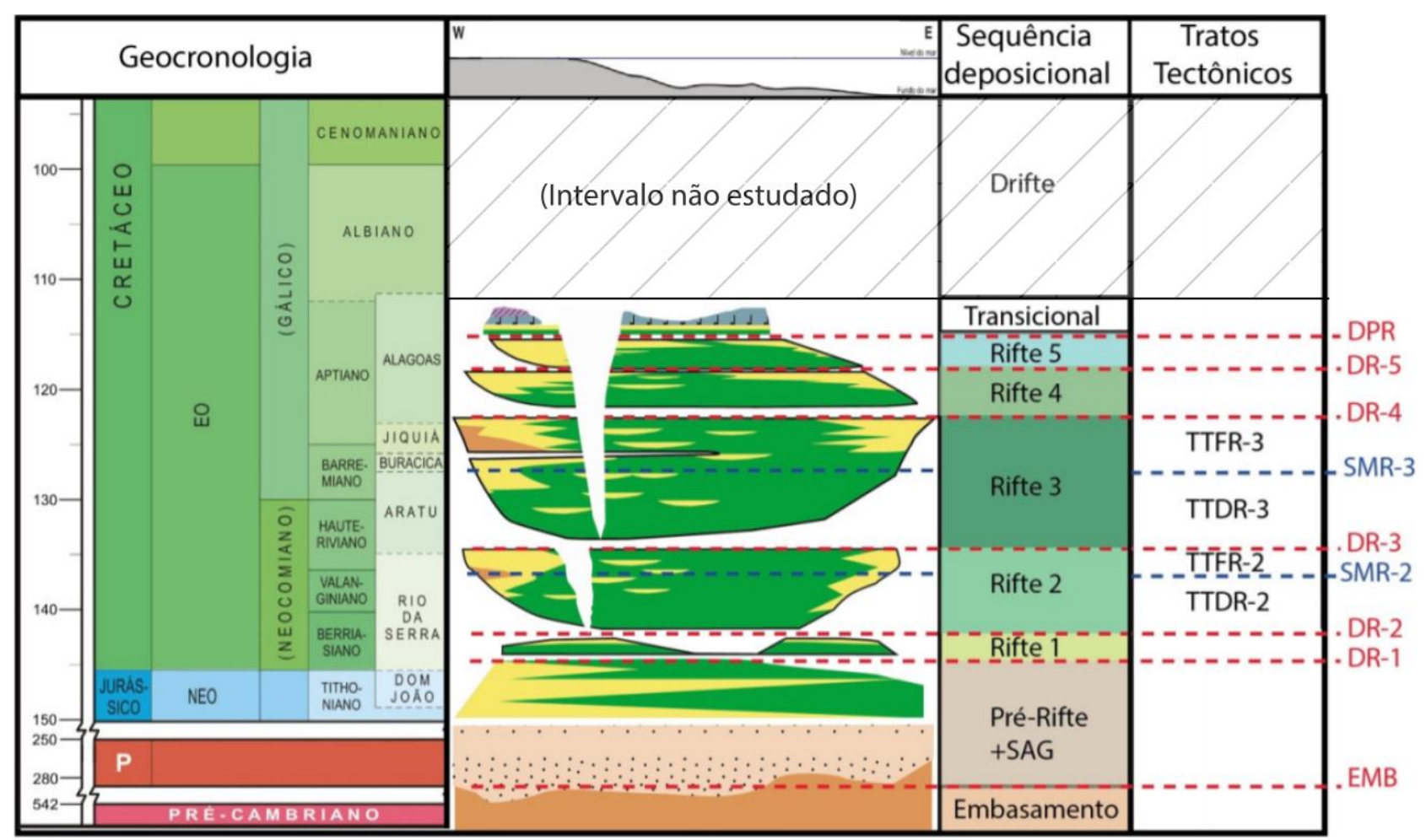

Figura 17 - Carta estratigráfica proposta para para a fase rifte do sul da Bacia de Camamu.

Para análise da sequência de segunda ordem, faz-se necessário seu mapa de espessura sísmica (Figura 18) e seções geológicas e estratigráficas de poços que abranjam uma área considerável.
O mapa de espessura sísmica do Rifte Total mostra que a sequência como um todo possui como principal depocentro a área norte que esteve sob influência da ZTS.

Outro depocentro está localizada no sul da 
área de estudo e é associado à criação de espaço gerado por uma flor negativa associada à ação da ZATM, foi interpretada sísmicamente.

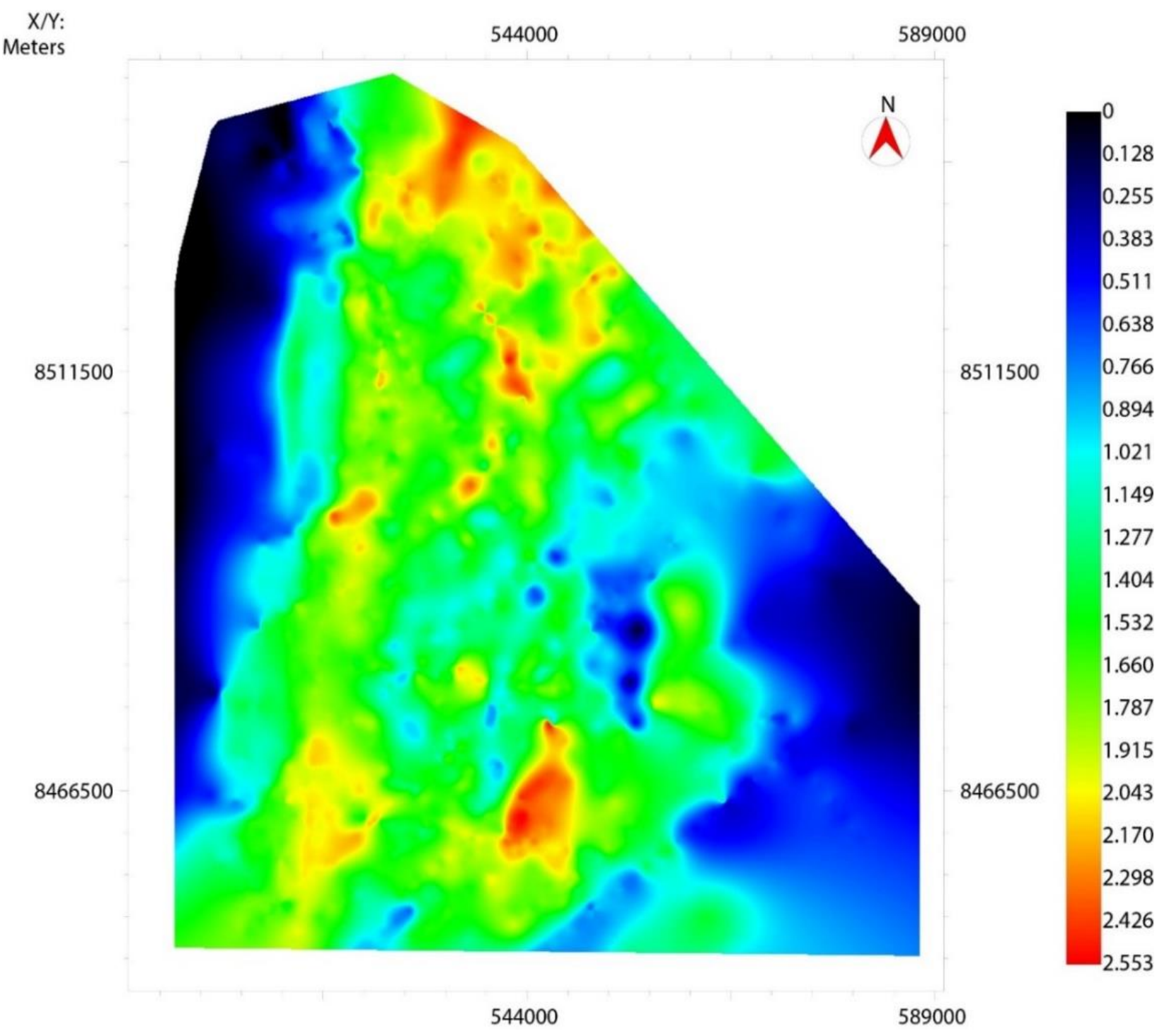

Há também grande concentração de depósitos entre a região proximal e distal que é separada por uma extensa falha normal associada ao talude.

Figura 18 - Mapa de espessura sísmica do Rifte Total. O principal depocentro está localizado à norte da área de estudo na região que sofreu efeito da Zona de Transcorrência de Salvador (ZTS).

O Rifte Total, visto como um conjunto de sequências de terceira ordem pode ser entendido pela compilação dos mapas de espessuras sísmicas de cada Sequência Rifte (Erro! Fonte de referência não encontrada.) e pelos mapas de isócronas de seus respectivos limites de sequências, isto é, discordâncias (Figura 20).

Para a figura 17 utilizou-se a mesma escalada de cores e range de tempo sísmico de modo que facilite a comparação entre as Sequências. A Sequência pré-rifte, apesar de possuir espessuras significativas, em torno de $600 \mathrm{~ms}$, é bastante homogênea, refletindo o caráter de quiescência tectônica.

A partir do mapa do Rifte 1, é possível ver a evolução da bacia através dos depocentros e falhas associadas (Figuras 21, 22).

Analisando o Rifte Total, o Rifte 1 seria associado a um TTIR, já que a tectônica apesar de ativa no norte da área de estudo, ainda é relativamente baixa nas demais áreas.

O Rifte 2 e 3 apresentam lagos extensos e com linhas formadas por contrastes de cores representando a grande ativação de falhas em toda a região. Estes seriam o equivalente ao TTDR para o Rifte Total. Para os Riftes 4 e 5, os lagos diminuem sua extensão e a criação de espaço através das falhas é menor, como mostra a diminuição de contrastes de cores nos respectivos mapas de espessura sísmica. 

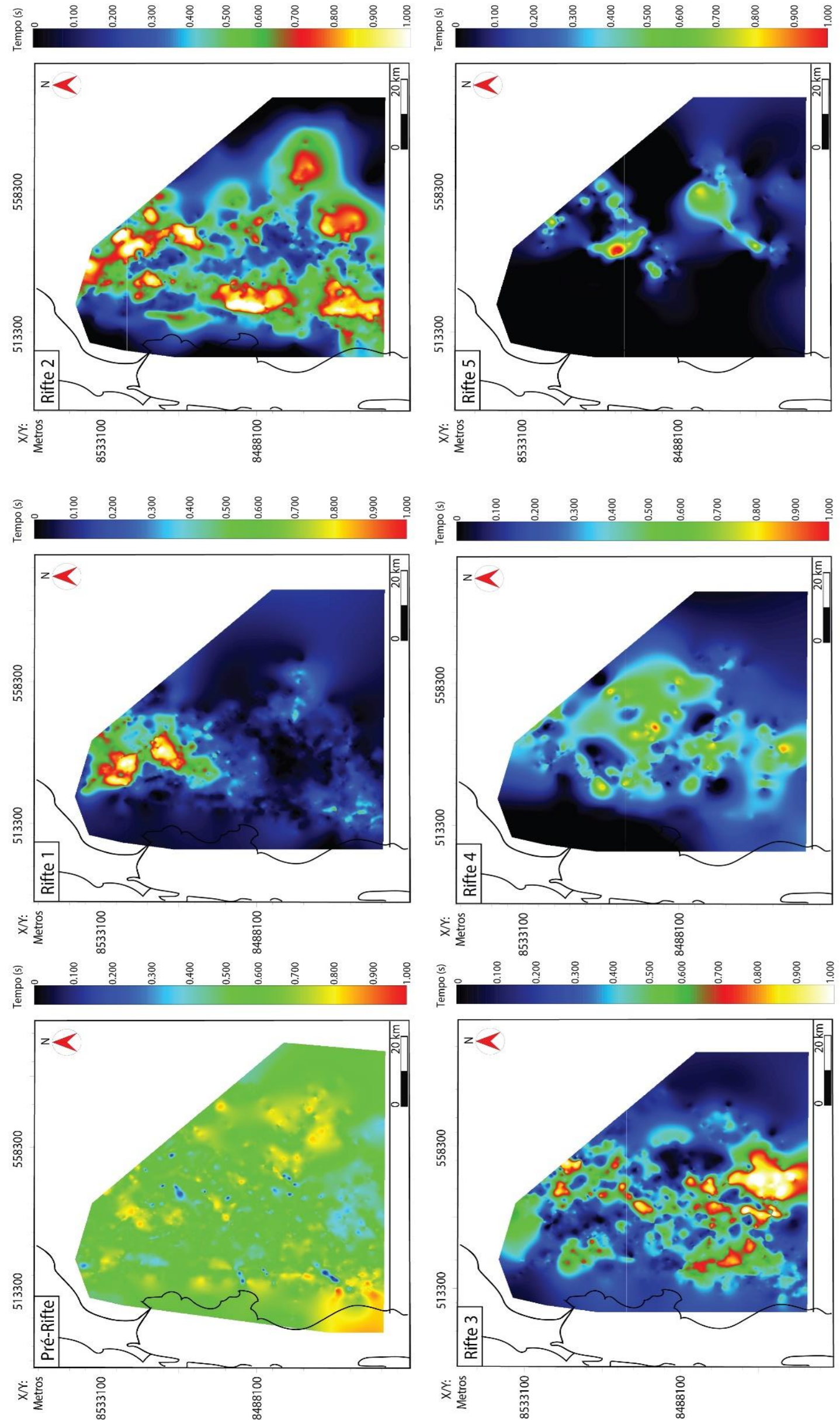

Figura 19 - Mapas de espessura sísmica das sequências Pré-rifte, Rifte 1, Rifte 2, Rifte 3, Rifte 4 e Rifte 5. 

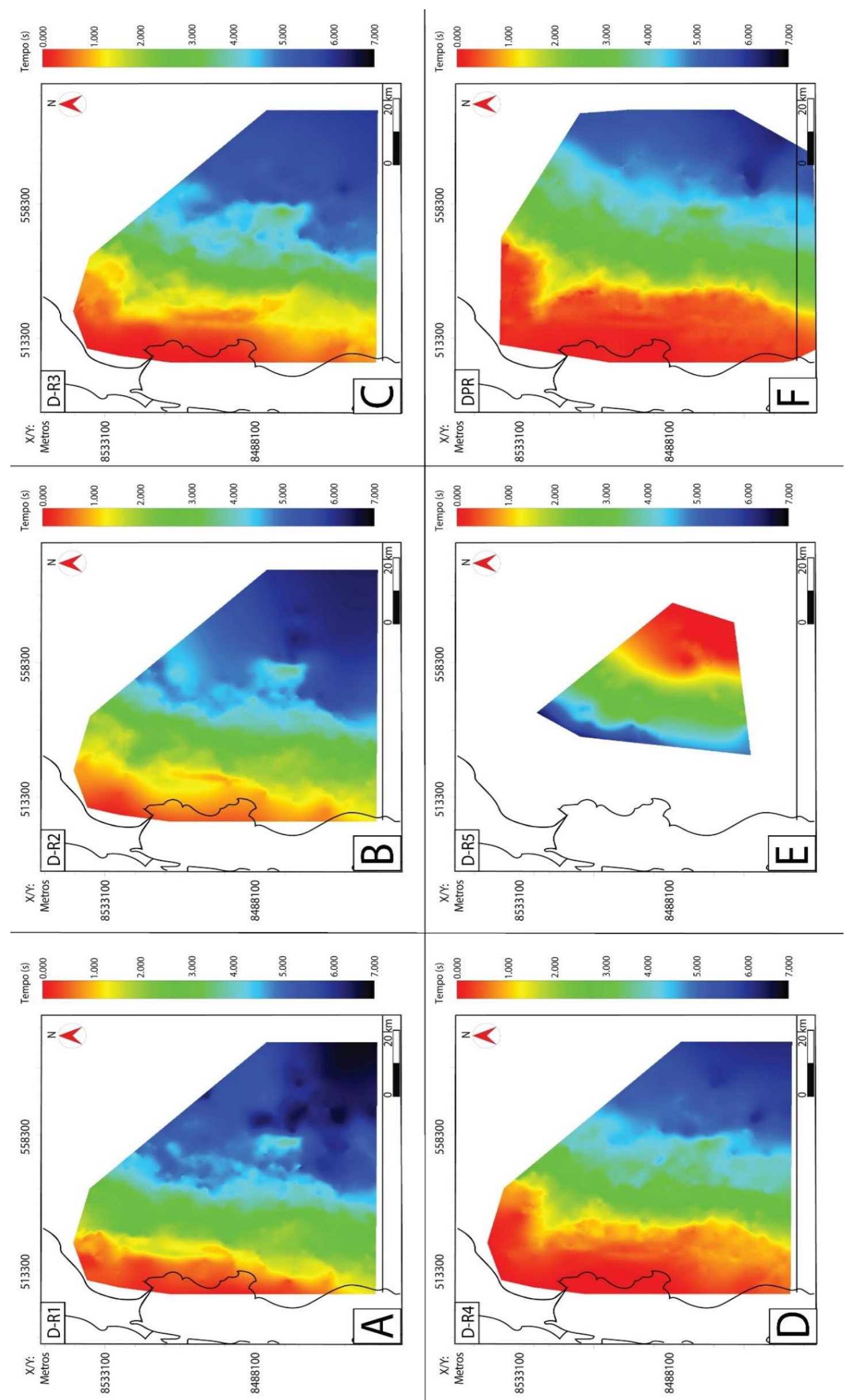

Figura 20 - Mapa de isócronas das discordância que limitam os Riftes. É possível notar desde a DR-2 até a DPR a feição em forma de "V" à norte na região proximal associada aos paleocanais mapeados. 
Nesse contexto de diminuição dos lagos, os sistemas flúvio deltaicos progradam assim como deve ser o TTFR.

As análises de poços foram mostradas até então de maneira isolada de modo a representar um contexto tectônico e de preenchimento da bacia temporalmente equivalente aos ciclos de terceira ordem e geograficamente localizados.
De modo que duas seções geológicas e estratigráficas foram feitas abrangendo a região proximal da área de estudo. Ambas as seções mostram com clareza a alta atividade tectônica durante o rifte dois, notar a criação de espaço na falha entre os poços 3 e 4 na seção 1 e 3 e 9 na seção 2, onde ocorrem os depósitos gravitacionais.

\section{SEÇÃO GEOLÓGICA 1}
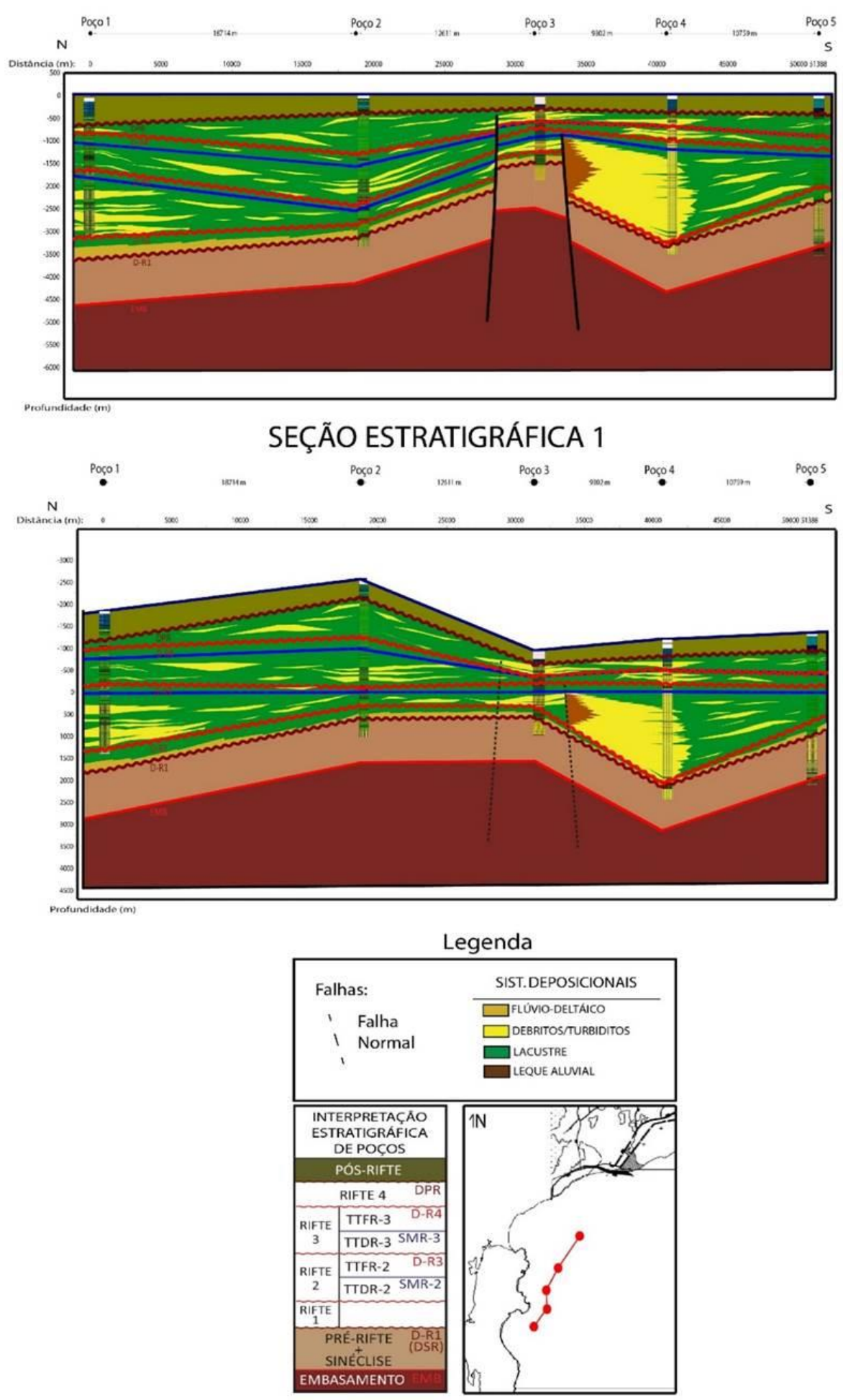

Figura 21 - Seção geológica e seção estratigráfica da região proximal da área de estudo e evidencia que os maiores depósitos nessa região estão associados ao Rifte 2 . 


\section{SEÇÃO GEOLÓGICA 2}

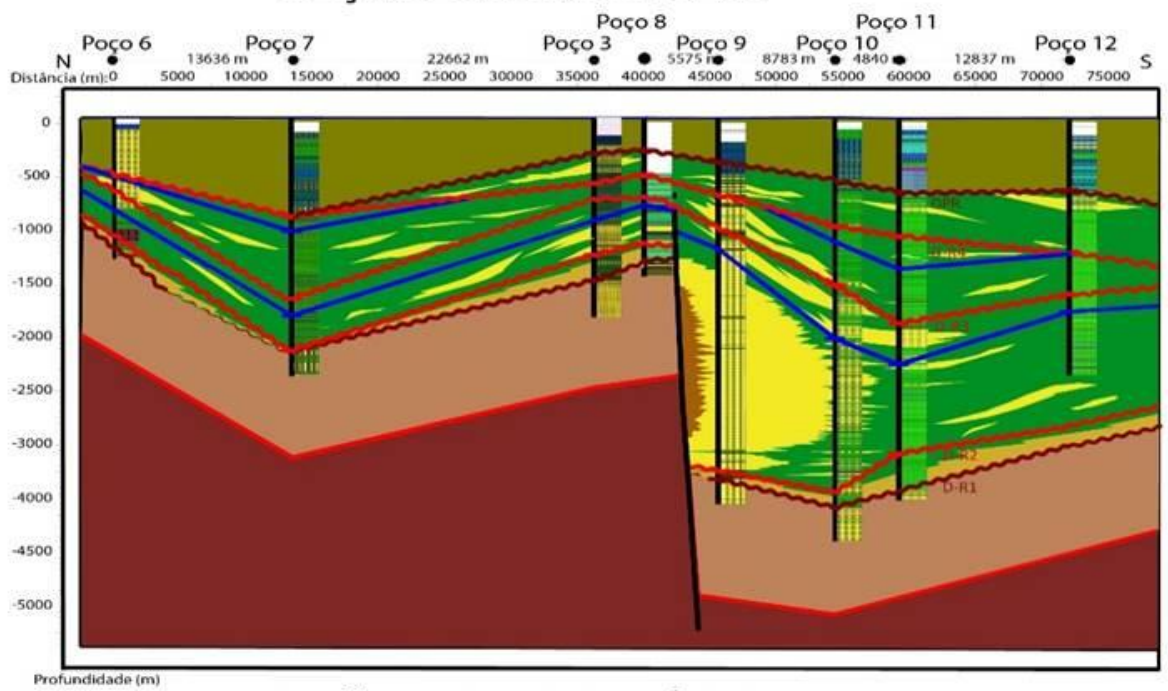

\section{SEÇÃO ESTRATIGRÁFICA 2}

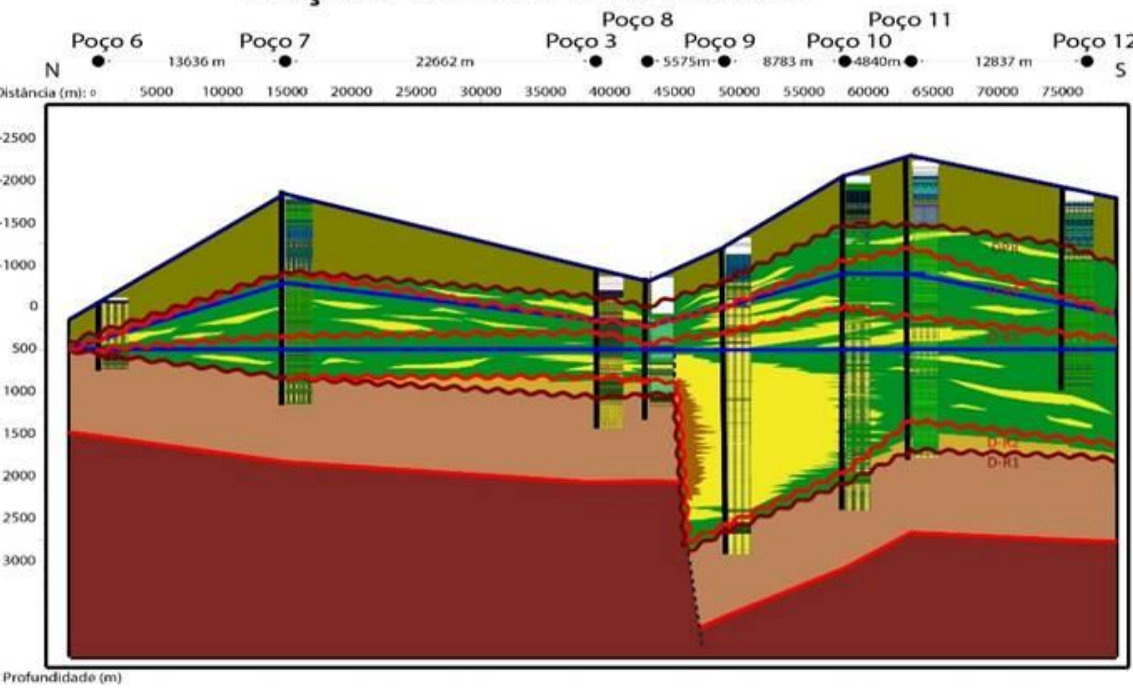

Legenda

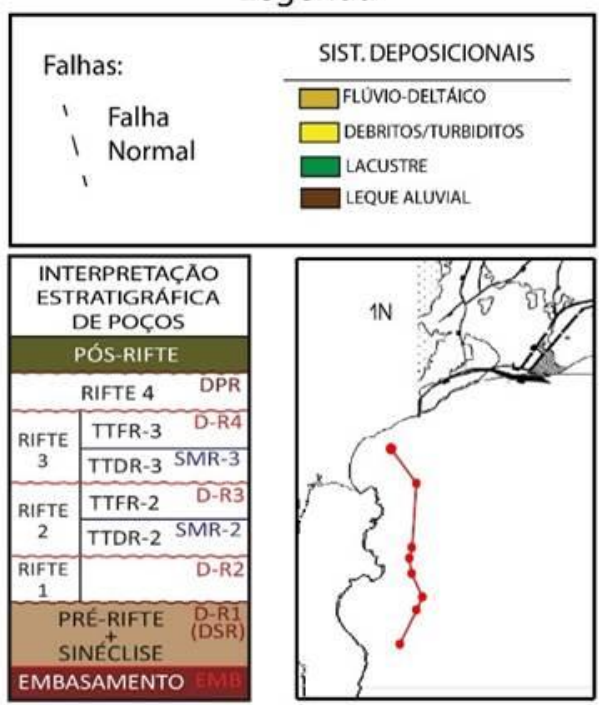

Figura 22 - Seção Geológica e estratigráfica de direção strike. A SMR-2 é utilizada como datum por representar o momento de maior afogamento da região.

\section{CONCLUSÕES}

O mapeamento de discordâncias internas à delimitação de cinco sequências deposicionais de fase rifte da Bacia de Camamu permitiu a terceira ordem. 
$\mathrm{Na}$ época de deposição do rifte 1 , falhas isoladas surgem criando lagos isolados com sedimentação predominantemente lacustre e flúvio-deltaica sem a presença de leques aluviais e fluxos gravitacionais. Esta sequência encontra-se bastante espessa na região proximal da ZTS, onde possivelmente houve maior criação de espaço e, portanto, possibilitando deposições espessas na região e desenvolvendo uma rede de drenagem com diversos canais mapeáveis que mantem tal feição até os dias atuais.

Durante o rifte 2 há um grande aumento na atividade tectônica e boa parte do sistema de falhas se conecta. Na região proximal há intensa criação de espaço de com deposição lacustre, corpos debríticos e turbidíticos e leques aluviais. Na região distal também há grande espessamento dessa sequência.

A sequência deposicional de terceira ordem Rifte 3 está associada à grande atividade tectônica. A bacia diminui a criação de espaço apenas na região proximal e difere neste aspecto do rifte 2 , já que seus depósitos mais espessos se concentram na região distal, especialmente próximo à ZATM. Os riftes 4 e 5 são depositados em um contexto no qual a bacia está diminuindo a atividade tectônica.

Devido à menor criação de espaço de acomodação que favorece a exposição dos depósitos de modo a ocorrer erosão, a DR-5, discordância que limita ambos os riftes pode ser encarada como uma discordância interna a uma sequência que seria a junção dos riftes 4 e 5 . Como este trabalho não conta com dados de datação, não há como confirmar tal possibilidade. A localização temporal destas sequências na carta estratigráfica proposta baseia-se em poços que associam a sequência Rifte 4 à Formação Taipus-Mirim.

Estruturalmente a porção Sul de Camamu é composta por falhas normais de direção preferencial N-S e possui três principais feições que ajudaram a moldar a atual forma geométrica da bacia: a Zona de Transcorrência de Salvador (ZTS), uma falha normal e central de grande rejeito e a Zona de Acomodação de TaipusMirim (ZATM).

\section{AGRADECIMENTOS}

Os autores agradecem à GEOPARK pelo financiamento do projeto RECAMU, à FAPESB e CAPES por bolsas de Pós-Graduação em Geofísica da UFBA. M.H. agradece ao CNPq por bolsa de produtividade em pesquisa (PQ 304657/15-8).

\section{REFERÊNCIAS}

CAIXETA, J.; MILHOMEM, P.; WITZKE, R.; DUPUY, I.; GONTIJO, G. Bacia de Camamu. Boletim de Geociências da Petrobrás, v. 15, n. 2, p. 455-461, 2007.

FERREIRA, T.; CAIXETA, J.; LIMA, D. Controle do embasamento no rifteamento das bacias de Camamu e Almada, Boletim de Geociências da Petrobrás, v. 17, p. 69-88, 2009.

GAWTHORPE, R. \& LEEDER, M. Tectono-sedimentary evolution of active extensional basins, Basin Research, v. 12, n. 3-4, p. 195-218, 2000.

HOLZ, M. Estratigrafia de Sequências. Histórico, Princípios e Aplicações. Editora Interciência. Rio de Janeiro. p. 191-192, 2012.

HOLZ, M.; MOREIRA, F.; TROCCOLI, E.B. A conceptual sequence stratigraphy model for continental rift successions based on the Recôncavo Basin, Cretaceous, Brazil. 2015. DOI: 10.13140/RG.2.1.3728.9846. Disp. em: < https://www.researchgate.net/publication/280742532_STRAT I_2015_A_conceptual_sequence_stratigraphy_model_for_con tinental_rift_successions_based_on_the_Reconcavo_Basin_Cr etaceous_Brazil>.
PROSSER, S. Rift-related linked depositional systems and their seismic expression. Geological Society, London, Special Publications, v. 71, n. 1, p. 35-66, 1993.

SANTOS, E.M. \& AMORIM, W.N. Princípio da sismocamada elementar e sua aplicação à Técnica de Volume de Amplitudes (TecVA). In: CONGRESSO INTERNACIONAL DA SOCIEDADE BRASILEIRA DE GEOFÍSICA, 9, 2005. Salvador. Anais...Salvador: Sociedade Brasileira de Geologia. VEEKEN, P.C.H. Seismic Stratigraphy, Basin Analysis and Reservoir Characterization. Handbook of Geophysical Exploration. Elsevier, 509 p., 2007.

VEEKEN, P. C. H. \& MOERKERKEN, B. Seismic stratigraphy and Depositional Facies Models. Academic Press. Chapter 4: p.215-374 (2013). 